\title{
The Social Contagion of Blood Donations: Sustaining Repeated Prosocial Behaviour
}

\author{
Joris M. Schröder ${ }^{1,2}$, Eva-Maria Merz ${ }^{1,2}$, Bianca Suanet ${ }^{1}$, and Pamala Wiepking ${ }^{1,3}$ \\ ${ }^{1}$ Department of Sociology, Vrije Universiteit Amsterdam, Amsterdam, the Netherlands \\ ${ }^{2}$ Department of Donor Studies, Sanquin Research, Amsterdam, the Netherlands \\ ${ }^{3}$ Lilly Family School of Philanthropy, Indiana University, Indianapolis, IN, United States
}

This version: July 27, 2022

\begin{abstract}
Repeated prosocial behaviour is crucial for the supply of many public goods. Experimental studies show that social mechanisms, such as social contagion, are pivotal for sustaining prosocial behaviour over time. This study examines social contagion in blood donations, an ideal-typical manifestation of real-world prosocial behaviour. We draw on longitudinal survey and register data on the Dutch blood donor population. Using a panel data model and an instrumental variable approach, we estimate that a one-unit increase in donations per inhabitant in the focal donor's neighbourhood is associated with an eleven percent increase in the focal donor's blood donations. This effect does not seem to be mediated by normative or informational social influence. Exploratory analysis further attributes this finding to social contagion within donor couples. The results of our study can be used to develop theories of repeated real-world prosocial behaviour, and to inform retention strategies of organizations that facilitate prosocial behaviour.
\end{abstract}

Keywords: prosocial behaviour, social contagion, blood donations, social influence, peer effects, collective action

Acknowledgements: We thank Femmeke Prinsze for her effort in collecting the blood donor data from the Dutch donor registry, and René Bekkers, Adrian Bruhin, Eamonn Ferguson, Caroline Graf, Elisabeth Naderlinger, Tijs van den Broek, Claire van Teunenbroek, and Beate Völker for valuable remarks on earlier versions of the manuscript.

Funding: This work was supported by the European Research Council (ERC) under the European Union's Horizon 2020 research and innovation programme [grant agreement No. 802227 to E.-M.M.]. Pamala Wiepking's 
position at the Lilly Family School of Philanthropy is funded by the Stead Family, her work at the Vrije Universiteit Amsterdam is funded by the Dutch Postcode Lotteries.

Contributions: All authors contributed to the study design and development of the main ideas. JS performed the statistical analyses and drafted the initial paper. All authors contributed significantly to revising the paper. 


\section{Introduction}

Many types of public goods are provided through the repeated prosocial behaviour of individuals (Fehr and Gächter 2002; Sugden 1984; Wilson and Musick 1997). The donation of blood is considered an ideal-typical example of such prosocial behaviour because it is voluntary, personally costly in terms of time and potential inconvenience, and generally benefits unknown others by enabling transfusions and many routine medical treatments (Healy 2000; Slonim, Wang, and Garbarino 2014). In addition, most blood donations come from very few repeat donors. In many countries, they make up less than five percent of the age-eligible population, and a substantial proportion of donors lapses every year (Masser et al. 2008; Piersma et al. 2017; Piliavin 1990) ${ }^{1}$. These blood donors contribute to a public good that we might all depend on to save our life.

A persistent puzzle across social sciences has been why some people repeatedly engage in prosocial behaviour over their life course, especially when this behaviour is costly to themselves. Studies of the collective action problem, i.e., that self-interest and collective interest seem to collide, suggest that informal social mechanisms make it possible for prosocial behaviour to be sustained over time (Simpson and Willer 2015). These social mechanisms include the simple exchange of information through communication, and the enforcement of social norms through rewards and punishments. In the absence of such social mechanisms, prosocial behaviour is typically not sustained and quickly decreases over time, as has been shown in numerous experimental studies (Chaudhuri 2011; Simpson and Willer 2015). One key social mechanism might be social contagion, broadly defined as a process where individuals change their behaviour in response to the behaviour of others ${ }^{2}$. This mechanism captures the crucial insight of positively related contributions to a public good: many individuals contribute if they believe others do so as well, and reduce their contribution if they believe others will no longer contribute (Chaudhuri 2011; Fischbacher and Gächter 2010). More specifically, this is the case when contributions by others are not sufficiently common to trigger a 'bystander effect', where the influence of others' contributions turns negative because of the perception that one's own contribution is no longer needed (Tsvetkova and Macy 2014).

Despite the accumulating evidence on social contagion of prosocial behaviour from experimental studies, the effects of social contagion on repeated real-world (i.e., non-experimental) prosocial behaviour remain unclear. Studies aiming to explain real-world prosocial behaviour are often individual-centred and focus on factors that motivate individuals to engage in prosocial behaviour, and less so the mechanisms that sustain this behaviour (Bekkers and Wiepking 2011; Irwin and Simpson 2013; Piersma et al. 2017). A strength of this line of research,

\footnotetext{
${ }^{1}$ Systems for collecting blood are diverse. Countries in the Global North (including the Netherlands) largely rely on voluntary and nonremunerated donations where donor and recipient remain anonymous to each other. Countries in the Global South more frequently rely on remunerated donations and sometimes on family-replacement systems (Slonim, Wang, and Garbarino 2014). See Healy (2000) for a discussion of how the proportion of blood donors in the population is affected by countries' collection regimes.

${ }^{2}$ Related terms in adjacent literatures are conditional cooperation, peer effects, social influence, or third-party influence. Manski 1993 terms this process endogenous social interaction effects, and distinguishes them from exogenous social interaction effects - changes in individuals' behaviour due to group member characteristics.
} 
however, is the study of individual-level mechanisms that explain how an individual's prosocial behaviour might be affected by the prosocial behaviour of others, including research on normative or informational social influence (Deutsch and Gerard 1955; White et al. 2009). Under normative social influence, individuals change their behaviour to conform to the perceived expectations of others. Under informational social influence, individuals change their behaviour based on new information obtained from prosocial behaviour by others.

In this study, we aim to combine insights from both strands of the literature: studies considering prosocial behaviour as collective action on the one hand, and studies taking an individual-centred approach to the analysis of repeated real-world prosocial behaviour on the other. Our goal is to assess how social contagion influences repeated real-world prosocial behaviour in the form of blood donations, and to test individual-level mechanisms that might drive social contagion. We draw on a survey conducted among a representative sample of the Dutch blood donor population in 2007-2009 and 2012-2013 ( $\mathrm{N}=15$ 090), and data from the Dutch blood bank on donation behaviour of the individuals surveyed and on other donors living in the same neighbourhood. We analyse how changes in an individual's donation behaviour are related to changes in the donation behaviour of other donors living in the same neighbourhood, whether such social contagion within neighbourhoods works between partners, family members, or friends, and what mechanisms might be at work. We use panel data models and an instrumental variable approach to reduce weaknesses regarding causal inference, which have been a major limitation of previous studies based on observational data. In what follows, we theoretically explore and empirically test how social contagion affects repeated blood donation behaviour, and to what extent social influence might underlie social contagion in prosocial behaviour.

\section{Theoretical Framework: Social Contagion Through Social Influence}

The question of how prosocial behaviour can be sustained over time has been a persistent one in the social sciences. Sociological theory on collective action views repeated prosocial behaviour as strongly dependent upon the social environment (Marwell and Oliver 1993; Simpson and Willer 2015). For example, in their review of the 'sociological foundations of cooperation and prosocial behavior' Simpson and Willer (2015, p. 43) highlight the basic insight that prosocial behaviour cannot be sustained in a social vacuum, but only in social settings that allow for social interactions between individuals. That is because social relations provide channels through which social mechanisms, such as social contagion (Tsvetkova and Macy 2014), norm enforcement through rewards and punishment (Fehr and Schurtenberger 2018), and the formation of social identities (Masser et al. 2008; Irwin and Simpson 2013), can work. In adjacent disciplines, interactions between potential contributors are similarly suggested as a solution to the collective action problem. Direct and indirect reciprocity (I help you and you help me, or I help you and somebody else helps me) are considered successful strategies for sustaining cooperation in in evolu- 
tionary biology (Nowak and Sigmund 2005). Moreover, many studies of public goods games have shown that most individuals are conditional cooperators: they increase or decrease their contribution depending on the contributions made by others, regardless of whether these will be reciprocated in the future (Chaudhuri 2011; Fischbacher and Gächter 2010; Thöni and Volk 2018). Thus, even if the contributions of others cannot be reciprocated, as is the case in most blood donation systems (Ferguson and Lawrence 2016), social contagion might play a role for sustaining repeated prosocial behaviour over time. In studies of collective action, prosocial behaviour is therefore not only seen as determined by individual and contextual characteristics, but also as clearly impacted by how other people in this context behave.

This fundamental insight into the relevance of interdependencies in prosocial behaviour has had limited impact, however, on sociological theories underlying empirical studies of repeated real-world prosocial behaviour, such as the integrated theory of volunteering (Wilson and Musick 1997; Wilson 2000) and the role identity model (Piliavin, Grube, and Callero 2002; Piliavin and Callero 1991). In developing the former, Wilson and Musick (1997, p. 695) ask: 'How long will you pick up litter in your neighborhood if you do not see anyone else doing it and your solitary effort has little impact?', and argue that 'clearly, your decision to volunteer is affected as much by what other people are thinking and doing as by what you are thinking and doing'. Altogether, however, the integrated theory of volunteering views social relations primarily as resources - social capital - that provide individuals with the means to volunteer. Social relations are therefore relevant because of the characteristics rather than the behaviour of others. In the role identity model, perceptions of how significant others feel about a person's behaviour contribute to becoming a volunteer. Additionally, the development of a role identity is dependent upon the social context, and it is seen as the crucial factor facilitating repeated prosocial behaviour. Part of the influence of others' behaviour might thus work through affecting individuals role identities. The Theory of Planned Behaviour (TPB) (Ajzen 1991)) has been the dominant theoretical basis for empirical studies explaining blood donation behaviour. It predicts that all contextual influences are mediated by the attitudes and intentions of individuals, and accordingly leaves no room for a direct effect of social contagion (Sniehotta, Presseau, and Araújo-Soares 2014). Recently, the applicability of literature on the collective action problem to blood donations has been assessed in the mechanisms of altruism (MOA) approach (Ferguson and Lawrence 2016), which views social contagion as a potential mechanism driving blood donation behaviour. So far, however, its predictions have not been tested empirically. Taken together, social contagion of behaviour has not until recently played a significant role in theoretical models of individuals' repeated prosocial behaviour, and blood donations in particular. While many theoretical approaches do incorporate some reference to processes of social influence, which we will review in a more systematic manner in the following sections, they do not directly reference social contagion between individuals as a factor that might influence repeated prosocial behaviour. Given the insights into the importance of interdependencies in prosocial behaviour from experimental studies, this might be a crucial oversight. 
If social contagion is a mechanism that alleviates the collective action problem, it must lead either to previous non-contributors contributing or to current contributors contributing more often. Forms of prosocial behaviour that require planning and deliberate repeated engagement, such as volunteering and giving blood, are often practised by a rather small proportion of the population. As mentioned above, the majority of blood donations are made by a small proportion of people that repeatedly donate. Examining how social contagion might affect individuals' repeated blood donation behaviour can therefore provide an important contribution to understanding how the provision of this life-saving public good can be sustained over time. In experimental studies, individuals are typically assigned to small groups composed of a few other individuals with whom they interact and whose behaviour is directly observable to them (Thöni and Volk 2018). In this study of real-world prosocial behaviour, we build on findings of the neighbourhood effects literature, which has shown that small scale geographical units are, to some degree, a relevant social environment (Dietz 2002; Galster 2012; Petrović, Manley, and Ham 2019). For the Netherlands, it has been shown that small-scale geographical areas do equally well as 'bespoke environments' in capturing neighbourhood effects (E. M. Veldhuizen, Stronks, and Kunst 2013). However, while small-scale geographical areas might be good approximations of the bespoke environment, they do not capture individuals' social networks very well. To assess which people within a neighbourhood might be most relevant for the social contagion of blood donations, we conduct further exploratory analyses based on individuals statements about the existence of blood donors within the social networks of the surveyed donors. The strength of social contagion is likely to increase with the social proximity between donors (Goette and Tripodi 2022), and, since our measure of the behaviour of others is based on geographical proximity, the physical proximity of other donors likely plays a role as well.

The only empirical evidence for social contagion among blood donors that we are aware of comes from Bruhin et al. (2020), who show that invitations to donate blood sent to pairs of donors living at the same address (many likely to be couples) are about $70 \%$ more effective in soliciting donations compared with invitations targeted at isolated donors. However, it is unclear to what extent social contagion influences repeated blood donation behaviour. Drawing on the comprehensive theoretical and empirical work on collective action, we hypothesize:

Hypothesis 1: The higher the number of blood donations by others, the higher the individual's number of blood donations.

Hypothesis 1 is at the core of our theoretical framework depicted in Figure 1. A direct association between own and others' prosocial behaviour, however, does not reveal why social contagion might contribute to sustaining individuals prosocial behaviour over time. To tackle this question, we draw on the individual-centred literature on attitudinal and cognitive determinants of prosocial behaviour, and set the concepts and constructs developed 
in this literature in relation to the actual donation behaviour of others. Thus, we assess whether the effect of social contagion is mediated by donors' attitudes. We conceptualize potential mechanisms along the lines of two frequently used explanations for social contagion in prosocial behaviour, namely normative and informational social influence (Deutsch and Gerard 1955; Frey and Meier 2004; van Teunenbroek, Bekkers, and Beersma 2020).

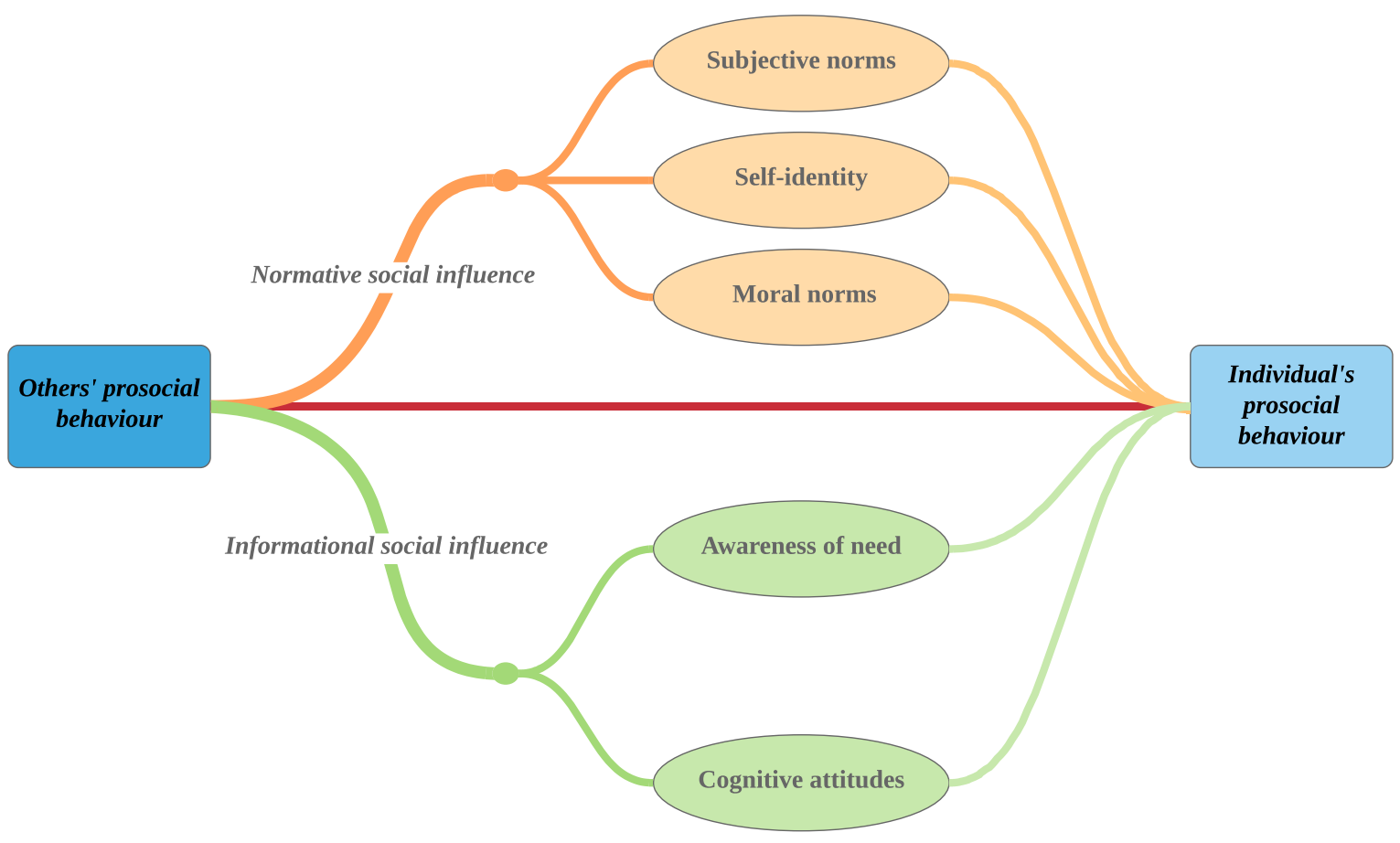

Figure 1 Theoretical model of mechanisms underlying social contagion in prosocial behaviour.

\subsection{Normative Social Influence}

Normative social influence is 'an influence to conform with the positive expectations of another' (Deutsch and Gerard 1955, p. 629). Below, we argue that normative social influence on blood donations might work in three ways. First, others' blood donation behaviour might affect individuals subjective norms about blood donation, that is, whether they perceive that relevant others expect them to donate. Second, others' blood donation behaviour might affect to what extent an individual self-identifies as a blood donor. And third, others' blood donation behaviour might affect individuals' moral norms about blood donations. In turn, subjective norms, self-identity, and moral norms about blood donation should affect individuals' repeated blood donation behaviour. 


\section{Subjective Norms}

Subjective norms reflect to what extent individuals believe others expect them to show a specific behaviour (Ajzen 1991; Armitage and Conner 2001b). Individuals want to comply with these expectations to maintain relationships or a good reputation (Armitage and Conner 2001a; Cialdini and Goldstein 2004; Ferguson and Lawrence 2016). While there is ample evidence that subjective norms about blood donations affect individuals' blood donation behaviour (Bednall et al. 2013), it is unclear how subjective norms about blood donation are formed. Two studies of blood donation behaviour have shown that personal norms for blood donations are related to perceptions about blood donation behaviour of others (Foss 1983; Piliavin and Libby 1986). These studies, however, did not take the actual behaviour of others into account. Krupka, Leider, and Jiang (2016) and Krupka and R. A. Weber (2013) have additionally shown that individuals derive subjective norms about prosocial behaviour from the actual behaviour of others in dictator games. We therefore hypothesize that social contagion in blood donations might partly work through changes in individuals' subjective norms:

Hypothesis 2: The positive effect of donations by others on individual blood donations is mediated by individuals' subjective norms about blood donations.

\section{Self-identity}

Sociological and social psychological theory emphasize that individuals possess not merely individual identities, but also social identities (Stryker and Burke 2000; Turner 1978). Accordingly, individuals view themselves and others in terms of meanings imparted by affiliation with societal groups or roles (Stets and Burke 2000). A self-identity is thus simultaneously defined via social position in a community and becomes a characteristic of a person's self (Charng, Piliavin, and Callero 1988). Being a blood donor can be such a self-identity (Masser et al. 2008).

Theoretical accounts argue that self-identities are made salient in contexts where individuals receive support in this identity or social relations are tied to a self-identity (Callero 1985; Charng, Piliavin, and Callero 1988; Stryker and Burke 2000), and that they emerge as others identify an individual with a specific role (Charng, Piliavin, and Callero 1988; Grube and Piliavin 2000; Turner 1978). These processes of group and role identification are more likely to take place in social contexts where more people are actively engaged in blood donation behaviour (Charng, Piliavin, and Callero 1988; Piliavin 1990). Empirically, Irwin and Simpson (2013) have shown that social identification with a group is stronger in more cooperative groups, and that a stronger social identity subsequently increases contributions to a public good. For blood donations, it has been found that self-identity as a blood donor is an important predictor of repeated blood donations (Bednall et al. 2013; Masser et al. 2008). We therefore hypothesize 
that:

Hypothesis 3: The positive effect of the donations by others on individual blood donations is mediated by individuals' self-identity as a blood donor.

\section{Moral Norms}

Many self-identities, particularly prosocially oriented ones such as being a blood donor, involve a moral component - a feeling of being morally obliged to perform a certain behaviour (Sparks and Guthrie 1998). Some scholars have argued that social norms for behaviour are internalized into moral norms (Armitage and Conner 2001a; Gintis et al. 2003), and that moral norms for a specific behaviour are constructed in a specific context, activated for example by receiving a request (Bekkers 2010; Piliavin and Libby 1986). In the context of a public goods game, J. M. Weber and Murnighan (2008) and Lindström et al. (2018) have shown that individuals perceive prosocial behaviour as more morally obligatory the more commonly they observe it. Because the violation of moral norms incurs costs, e.g., in the form of guilt, higher moral norms about prosocial behaviour should increase repeated prosocial behaviour (Gintis et al. 2003). This has also been shown for the case of blood donations (Masser et al. 2008). We hypothesize that:

Hypothesis 4: The positive effect of donations by others on individual blood donations is mediated by individuals' moral norms about blood donations.

\subsection{Informational Social Influence}

Informational social influence is 'to accept information obtained from another as evidence about reality' (Deutsch and Gerard 1955, p. 629), which can lead to attitude change (Wood 2000). Below, we outline that awareness of need for blood donations and cognitive attitudes about blood donations might be derived from the donation behaviour of others, and in turn affect blood donation behaviour.

\section{Awareness of Need}

Awareness of need has been identified as a central factor motivating prosocial behaviour in empirical studies of charitable giving (Bekkers and Wiepking 2011; van Teunenbroek, Bekkers, and Beersma 2020), and awareness of need for blood donations is also among frequently self-reported motivations for donating blood (Ferguson, Hill, et al. 2020). Theoretically, the effect of donations by others on awareness of need might be positive or negative. A 
negative relationship follows from models of pure altruism (Becker 1974), impure altruism (Andreoni 1990), and diffusion of responsibility (Darley and Latane 1968), where individuals are concerned with addressing a given need, and the donations of an individual and of others are largely seen as substitutes in achieving this goal. A positive relationship follows from the assumption that donations by others make the need for blood donations apparent in the first place (Omoto and Snyder 2002; Schervish and Havens 1997). Tsvetkova and Macy (2014) have linked these two perspectives by hypothesizing that contributions by others initially increase own contributions up to a point where others' contributions are fairly common, and decrease own contributions from this point onwards. This assumption is supported by their experimental study, where an own contribution is more likely when up to $33 \%$ of others contribute in comparison to when no others contribute. Because only a small proportion of adults in the Netherlands donate blood, donations by others should increase rather than decrease awareness of need for blood donations. We therefore hypothesize that:

Hypothesis 5: The positive effect of donations by others on individual blood donations is mediated by individuals' awareness of need for blood donations.

\section{Cognitive Attitudes}

Cognitive attitudes refer 'to the degree to which a person has a favorable or unfavorable evaluation or appraisal of the behavior in question' (Ajzen 1991, p. 188). Several studies have shown that cognitive attitudes about blood donation positively affect the donation behaviour of current blood donors (Bednall et al. 2013). According to the TPB, cognitive attitudes are determined by expectations about the outcome of performing the behaviour (Ajzen 1991). Through its impact on these expectations, the prosocial behaviour of others might change individuals' cognitive attitudes about blood donations, e.g., whether performing the behaviour is seen as something positive or worthwhile. For example, the donation behaviour of others might be perceived as a 'quality signal' for the cause of blood donations, indicating that a cause is worth enduring personally costly behaviour (Frey and Meier 2004; van Teunenbroek, Bekkers, and Beersma 2020; Vesterlund 2003). We hypothesize that:

Hypothesis 6: The positive effect of the donations of others on individual blood donations is mediated by individuals' cognitive attitudes about blood donations. 


\section{Data}

Our two main data sources are the Donor InSight study (DIS; see Timmer et al. (2019) for information on collection procedures) and the Dutch Donor Registry (Sanquin 2020). DIS is a longitudinal survey of a representative sample of the Dutch blood and plasma donor population in 2007-2009 (DIS-I, N=31,338) and 2012-2013 (DIS-II, N=34,826, of whom 22,132 (63.6\%) also participated in DIS-I). Response rate, calculated as the number of completed surveys received divided by the number of surveys sent out, was $62.7 \%$ for DIS-I, and $69.6 \%$ for DIS-II (for details see Timmer et al. (2019)). The Dutch Donor Registry records individuals' blood donations, donation invitations, donor addresses as six-digit postcodes, and donor demographics.

\subsection{Sample}

Of the 22,132 individuals who participated in both DIS waves, we include 19,149 (86\%) who donated whole blood at least once since 2007. We exclude 1,645 (7\%) plasma donors, because these follow a different invitation procedure and are allowed to donate much more frequently than whole blood donors. We further exclude 1,133 (5\%) participants who were too old to donate (older than 70), and 1,281 (6\%) individuals who started donating only after the start of the study period from 2007-2014. Our analyses thus draw on a sample of 15,090 blood donors observed in both 2007-2009 and 2012-2014.

\subsection{Variables}

Table 1 provides descriptive statistics for the variables used in the empirical analysis. Table S1 in the Supplementary Material shows a matrix of correlations among these variables. Below, we describe the central study measures in more detail.

\section{Individuals' Whole Blood Donation Attempts}

The dependent variable (DV) in this study is the individuals' number of whole blood donation attempts in 20072009 and in 2012-2014, as registered in the Donor Registry. We use blood donation attempts instead of only successful blood donations, because donation attempts better capture individuals' prosocial behaviour (i.e., turning up to donate irrespective of cases where donors had to be deferred from making a donation for medical reasons such as low haemoglobin levels). The number of donation attempts provides a measure of repeated prosocial behaviour within these periods. Figure 2 shows a histogram of the number of individuals' whole blood donation attempts in the two periods from 2007-2009 and 2012-2014. In the first period, donors averaged 3.93 donations, in the second 3.23 donations. The most notable difference is that an additional 1,600 (11\%) donors made no donation 


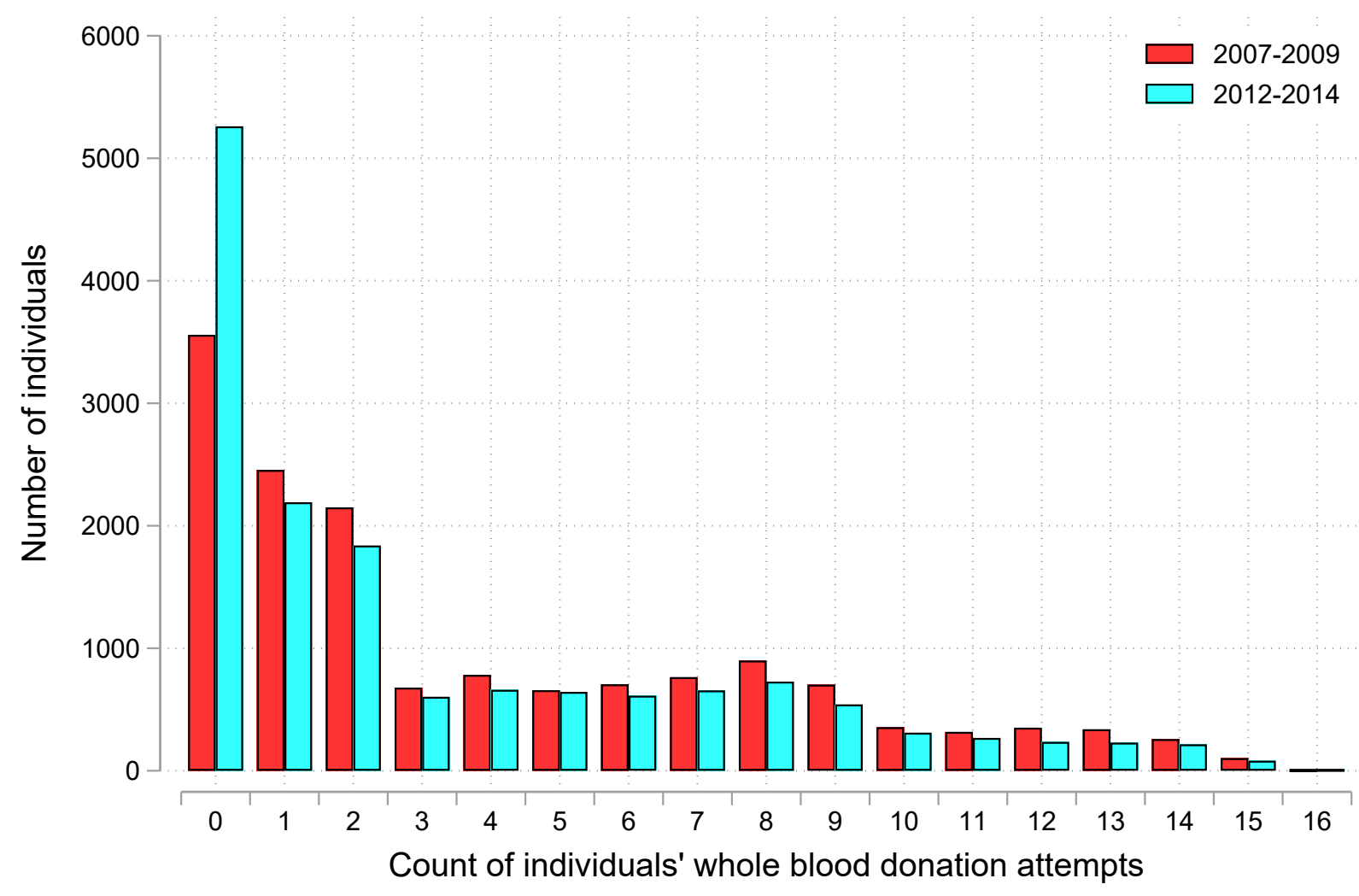

Figure 2 Histogram of the count of the individuals' whole blood donation attempts in 2007-2009 and 2012-2014, N $=15,090$.

attempt in the second period compared to the first period (note that individuals above the age-eligibility threshold were already excluded).

\section{Donation Attempts per Inhabitant}

To capture the donation behaviour of others, we use the number of donation attempts per inhabitant within the focal donor's six-digit postcode. The six-digit postcodes of the Netherlands are small-scale geographical units (there are about 430,000 of them), with on average 58 inhabitants in our sample (Median $=50$, Min $=5$, Max $=$ $1,240)$. The number of donation attempts per inhabitant is the ratio between the number of whole blood donation attempts by other donors living within the same postcode as the focal donor and the number of inhabitants in the postcode. The number of inhabitants per six-digit postcode is provided by Statistics Netherlands (Centraal Bureau voor de Statistiek (CBS) 2020). We use the number of inhabitants on 1 January 2010 to create the variable for the first period, and the number of inhabitants on 1 January 2014 to create the variable for the second period. 
Table 1 Summary statistics of study variables

\begin{tabular}{lcrrrrc}
\hline & Mean or \% & \multicolumn{1}{c}{ Min } & \multicolumn{1}{c}{ Max } & \multicolumn{1}{c}{ SD } & SD betw. & SD within \\
\hline Individuals' donation attempts & 3.58 & 0.00 & 16.00 & 3.99 & 3.67 & 1.56 \\
Donation attempts per inhabitant & 0.10 & 0.00 & 3.00 & 0.15 & 0.13 & 0.07 \\
Invitations to donate per inhabitant & 0.23 & 0.00 & 3.80 & 0.29 & 0.26 & 0.14 \\
Male & $45.10 \%$ & 0.00 & 1.00 & & & \\
Income & 3.83 & 1.00 & 7.00 & 1.57 & 1.57 & 0.00 \\
Age & 48.29 & 19.59 & 68.50 & 11.44 & 11.26 & 2.00 \\
Working hours & 26.71 & 0.00 & 95.00 & 15.62 & 14.55 & 6.13 \\
ln(working hours+1) & 2.85 & 0.00 & 4.56 & 1.35 & 1.25 & 0.56 \\
Having children & $76.20 \%$ & 0.00 & 1.00 & & & \\
Individuals' invitations to donate & 7.25 & 0.00 & 35.00 & 6.62 & 5.96 & 2.88 \\
ln(Individuals' invitations +1$)$ & 1.62 & 0.00 & 3.58 & 1.12 & 1.01 & 0.48 \\
Previous donations & 28.89 & 0.00 & 147.65 & 22.28 & 22.28 & 0.00 \\
Permanently deferred & $7.40 \%$ & 0.00 & 1.00 & & & \\
Subjective norms & 0.00 & -1.94 & 1.87 & 0.88 & 0.82 & 0.33 \\
Self-identity & 0.00 & -3.72 & 2.27 & 0.93 & 0.88 & 0.30 \\
Moral norms & 0.00 & -2.22 & 2.19 & 0.90 & 0.86 & 0.29 \\
Awareness of need & 0.01 & -4.84 & 1.15 & 0.81 & 0.76 & 0.28 \\
Cognitive attitudes & 0.00 & -7.69 & 0.84 & 0.79 & 0.69 & 0.38 \\
Generalized social trust & 0.00 & -3.79 & 2.51 & 0.85 & 0.85 & 0.07 \\
Altruism & 0.00 & -3.95 & 2.11 & 0.88 & 0.83 & 0.30 \\
Self-efficacy & 0.00 & -5.37 & 1.03 & 0.95 & 0.80 & 0.50 \\
Affective attitudes & 0.00 & -3.34 & 1.86 & 0.94 & 0.86 & 0.37 \\
\hline
\end{tabular}

SD betw. = standard deviation of variable between individuals. SD within = standard deviation of variable within individuals over time. Descriptive statistics for attitudinal measures (Subjective norms - Affective attitudes) are predicted factors scores based on the measurement model (see Table 2). For these measures, higher values indicate more of the measured construct.

\section{Mediators}

The measures capturing normative social influence, namely subjective norms about blood donation, self-identity as a blood donor, and moral norms about blood donation, are based on scales commonly used in extensions of the TPB (Ajzen 1991), adapted to the blood donation context in previous work (Charng, Piliavin, and Callero 1988; Merz, van den Hurk, and de Kort 2017; I. Veldhuizen et al. 2011). Table 2 shows the items used to measure these constructs. Each of them was measured using a five-point Likert scale ranging from 'completely disagree' to 'completely agree'. Item 1 of subjective norms additionally included 'does not apply, I do not have a partner' as a response option, which was recoded to 1 (completely disagree), to reflect that these individuals are not subject to influence by partners. To measure awareness of need for blood donations, we use responses to the two questions given in Table 2, which were also measured using a five-point Likert-type scale. Cognitive attitudes towards blood donation were elicited using a semantic-differential scale, where respondents fill out a five-point rating option based on the bipolar adjective pairs given in Table 2 . 
Table 2 Confirmatory factor analysis of attitudinal measures: standardized factor loadings, standard errors, and composite reliabilities

\begin{tabular}{|c|c|c|c|c|}
\hline & \multicolumn{2}{|c|}{ Period 1} & \multicolumn{2}{|c|}{ Period 2} \\
\hline & $\lambda$ & S.E. & $\lambda$ & S.E. \\
\hline \multicolumn{5}{|l|}{ Subjective norms about blood donation $\left(\mathbf{C R}_{t 1}=\mathbf{0 . 7 0 8}, \mathbf{C R} t 2=\mathbf{0 . 7 0 6}\right)$} \\
\hline $\begin{array}{l}\text { 'My partner thinks I should continue giving blood } \\
\text { as long as my health allows it.' }\end{array}$ & 0.631 & 0.006 & 0.644 & 0.006 \\
\hline $\begin{array}{l}\text { 'My family and friends think that I should continue giving blood } \\
\text { as long as my health allows it.' }\end{array}$ & 0.841 & 0.007 & 0.828 & 0.007 \\
\hline \multicolumn{5}{|l|}{ Self-identity as a blood donor $\left(\mathbf{C R}_{t 1}=\mathbf{0 . 6 8 8}, \mathbf{C R}_{t 2}=\mathbf{0 . 6 9 9}\right)$} \\
\hline 'Being a blood/plasma donor is an important part of who I am.' & 0.686 & 0.005 & 0.699 & 0.005 \\
\hline 'Being a blood donor means more to me than just giving blood.' & 0.638 & 0.005 & 0.648 & 0.005 \\
\hline 'I would feel sorry if I could no longer give blood.' & 0.629 & 0.004 & 0.633 & 0.005 \\
\hline \multicolumn{5}{|l|}{ Moral norms about blood donation $\left(\mathbf{C R}_{t 1}=\mathbf{0 . 7 3 5}, \mathbf{C R}_{t 2}=\mathbf{0 . 7 2 3}\right)$} \\
\hline 'I feel morally obliged to give blood.' & 0.514 & 0.005 & 0.511 & 0.005 \\
\hline 'I would feel guilty if I did not give blood.' & 0.791 & 0.004 & 0.775 & 0.004 \\
\hline 'Not giving blood is actually against my principles.' & 0.759 & 0.004 & 0.747 & 0.004 \\
\hline \multicolumn{5}{|l|}{ Awareness of need for blood donations $\left(\mathbf{C R}_{t 1}=\mathbf{0 . 5 2 5}, \mathbf{C R}_{t 2}=\mathbf{0 . 5 3 5}\right)$} \\
\hline 'My blood is needed.' & 0.728 & 0.008 & 0.695 & 0.008 \\
\hline $\begin{array}{l}\text { 'I have the feeling that it would not matter } \\
\text { if I gave blood.' [reverse coded] }\end{array}$ & 0.454 & 0.007 & 0.508 & 0.007 \\
\hline \multicolumn{5}{|l|}{ Cognitive attitudes towards blood donation $\left(\mathbf{C R}_{t 1}=\mathbf{0 . 5 4 8}, \mathbf{C R}_{t 2}=\mathbf{0 . 5 8 5}\right)$} \\
\hline \multicolumn{5}{|l|}{ 'I find giving blood ... } \\
\hline good - bad [reverse coded] & 0.432 & 0.007 & 0.536 & 0.007 \\
\hline meaningless - worthwhile.' & 0.525 & 0.007 & 0.543 & 0.007 \\
\hline \multicolumn{5}{|l|}{ Generalized social trust $\left(\mathbf{C R}_{t 1}=\mathbf{0 . 5 2 3}, \mathbf{C R}_{t 2}=\mathbf{0 . 5 2 8}\right)$} \\
\hline 'In general, most people can be trusted.' & 0.566 & 0.007 & 0.578 & 0.007 \\
\hline $\begin{array}{l}\text { 'You can not be careful enough when you are } \\
\text { dealing with other people.' [reverse coded] }\end{array}$ & 0.624 & 0.007 & 0.620 & 0.007 \\
\hline \multicolumn{5}{|l|}{ Altruism $\left(\mathbf{C R}_{t 1}=\mathbf{0 . 7 0 9}, \mathbf{C R}_{t 2}=\mathbf{0 . 7 1 1}\right)$} \\
\hline $\begin{array}{l}\text { 'I prefer to work towards my own wellbeing } \\
\text { than towards the wellbeing of others.' [reverse coded] }\end{array}$ & 0.433 & 0.006 & 0.431 & 0.006 \\
\hline 'I try to work towards the wellbeing of society.' & 0.549 & 0.005 & 0.555 & 0.005 \\
\hline 'I am not very interested in helping others.' [reverse coded] & 0.417 & 0.006 & 0.424 & 0.006 \\
\hline 'It is important to me that I help others.' & 0.720 & 0.005 & 0.719 & 0.005 \\
\hline 'I think it is important to help the poor and the needy.' & 0.719 & 0.005 & 0.716 & 0.005 \\
\hline \multicolumn{5}{|l|}{ Self-efficacy $\left(\mathbf{C R}_{t 1}=\mathbf{0 . 8 9 9}, \mathbf{C R}_{t 2}=\mathbf{0 . 8 7 2}\right)$} \\
\hline $\begin{array}{l}\text { 'If I wanted to, I would be able to continue giving blood as long } \\
\text { as my health allows it.' }\end{array}$ & 0.727 & 0.004 & 0.763 & 0.004 \\
\hline $\begin{array}{l}\text { 'When I receive an invitation to give blood, I consider it a matter } \\
\text { of course to do so.' }\end{array}$ & 0.715 & 0.004 & 0.677 & 0.004 \\
\hline 'I am planning to continue giving blood as long as my health allows it.' & 0.858 & 0.002 & 0.800 & 0.003 \\
\hline $\begin{array}{l}\text { 'I will continue to be a blood donor until it is no longer possible for me } \\
\text { to donate.' }\end{array}$ & 0.834 & 0.003 & 0.664 & 0.004 \\
\hline $\begin{array}{l}\text { 'When I receive an invitation from the blood bank, I automatically } \\
\text { go to give blood.' }\end{array}$ & 0.639 & 0.004 & 0.654 & 0.004 \\
\hline 'I think that I will continue to give blood as long as my health permits it.' & 0.846 & 0.002 & 0.809 & 0.003 \\
\hline \multicolumn{5}{|l|}{ Affective Attitude Towards Blood Donation $\left(\mathbf{C R}_{t 1}=\mathbf{0 . 8 6 8}, \mathbf{C R}_{t 2}=\mathbf{0 . 8 8 3}\right)$} \\
\hline pleasant - unpleasant [reverse coded] & 0.775 & 0.003 & 0.809 & 0.003 \\
\hline annoying - enjoyable & 0.907 & 0.002 & 0.920 & 0.002 \\
\hline unappealing - appealing.' & 0.799 & 0.003 & 0.805 & 0.003 \\
\hline
\end{tabular}

Notes: $\lambda=$ standardized factor loading; S.E. $=$ standard error; $\mathrm{CR}=$ composite reliability estimate; RMSEA = 0.046; CFI = 0.851; TLI = 0.836. 


\subsection{Covariates}

Our models include donor age in years, sex $(0=$ female, $1=$ male $)$, having children $(0=$ no, $1=$ yes $)$, the natural logarithm of working hours per week, monthly net income in seven categories, the overall number of blood donations prior to 2007 , being permanently deferred $(0=$ no, $1=$ yes $)$, the natural logarithm of invitations received to donate from the blood bank, generalized social trust (GST), altruism, self-efficacy, and affective attitudes towards blood donation as covariates. These variables have been found to affect blood donation behaviour in previous studies (Bednall et al. 2013; Piersma et al. 2017; Merz, van den Hurk, and de Kort 2017), and might be confounders of the relationship between own and others donations if they also affect others' blood donation behaviour via homophily. The number of donation invitations and individuals' working hours were log-transformed to better meet the linearity assumption of the Poisson model described below (see Supplementary Material S1.3). Details of the measurement of attitudinal variables can be found in Table 2, and details of the measurement of the remaining covariates are given in the study's preregistration available at https://doi.org/10.17605/OSF.IO/WJYVG.

\section{Methods}

There are two main concerns of endogeneity when estimating the effect of others' donations on the focal donors donations. First, that the donations by others and the potential mediators might be correlated with unobserved time-constant heterogeneity between individuals that affect their donation behaviour. To address this concern, we use a correlated random effects (CRE) panel data model. Second, it might be that the explanatory variables are correlated with time-varying unobserved factors, for example external shocks like the closing or opening of specific donation locations. To address this concern, we use a CRE instrumental variable (IV) approach that simultaneously addresses potential endogeneity with regard to time-constant and time-varying unobservables (Lin and Wooldridge 2019). Both approaches are described in more detail in section 4.2.

We implement these approaches in a structural equation modelling (SEM) framework. A SEM consists of two major components: a measurement model and a structural model (Bollen and Noble 2011). The measurement model describes how latent constructs, such as our mediators, are related to the observed measures (e.g., survey items). The structural model describes the relationships between the variables, as predicted by hypotheses 1-6. We first estimate the measurement model using full information maximum likelihood, and subsequently include the predicted factor scores of the latent variables in the structural model $^{3}$.

We preregistered our hypotheses, the operationalization of variables, and an analysis plan through the Open Science Framework: https://doi.org/10.17605/OSFIO/WJYVG. We depart from the preregistered analysis plan by

\footnotetext{
${ }^{3}$ This is to avoid numerical integration across many dimensions, which is required in maximum likelihood estimation of a nonlinear model including continuous latent variables and would make the estimation duration unfeasible and the results potentially inaccurate (Rockwood 2021).
} 
additionally including permanent deferral from donating blood as a covariate, which slightly increases precision but does not change the results substantially. Further, we do not rerun our analyses with donations by others aggregated based on four-digit postcodes. These are much larger in size and, as our results will demonstrate, are therefore unlikely to accurately capture the donation behaviour of relevant others.

Statistical analyses are carried out in Stata 16 (StataCorp. 2019). The models are estimated using quasi-maximum likelihood estimation (QMLE) to obtain standard errors that are robust to heteroskedasticity (e.g., violations of the Poisson models' assumption of equidispersion, which is also further examined in Supplementary Material S1.3.) (Cameron and Trivedi 2013; Wooldridge 2013; StataCorp. 2016).

\subsection{Measurement Model}

In the measurement model, survey items that make up latent constructs are included in a confirmatory factor analysis (CFA). Through CFA, the variance of the items measuring a construct is split up into the items' unique variances, understood as measurement error, and the common variance shared between the items, capturing the underlying construct (StataCorp. 2016; Kline 2016). We assume scalar longitudinal measurement invariance over time, meaning that the psychometric properties of constructs do not change with repeated measurements. Latent variables are therefore measured by the same items in both periods, and intercepts and path coefficients of the measurement model are constrained to be equal in both waves (Baldwin 2019). Results of the CFA are displayed in Table 2. All indicators load significantly on the latent constructs. The composite reliability estimates (CR) suggest that convergent validity of most constructs is acceptable, with estimates being around or above 0.7 . The measures of awareness of need, cognitive attitudes, and GST, however, have worse convergent validity, as indicated by composite reliability estimates of around 0.55 , which is below the commonly suggested threshold of 0.6 (Bagozzi and Yi 1988). To stick to commonly used scales and our preregistered analysis plan, we do not respecify the CFA based on composite reliability. Regarding discriminant validity, most correlations between predicted factor scores are at most moderate in size (see Table S1), suggesting reasonable discriminant validity between constructs (Kline 2016). We find strong correlations of self-identity with moral norms $(r=0.76)$ and self-efficacy $(r=0.70)$, indicating that these constructs measure similar concepts. We discuss their potentially interrelated impact on donation behaviour below.

\subsection{Structural Model}

We use a CRE Poisson regression for modelling the count of an individuals' blood donation attempts in each of the periods from 2007-2009 and 2012-2014. The Poisson model specifies that the number of donation attempts $y_{i}$ given the predictors $x_{i}$ follows a Poisson distribution 


$$
\operatorname{Pr}\left(y_{i} \mid x_{i}\right)=\frac{\exp \left(-\mu_{i}\right) \mu_{i}^{y_{i}}}{y_{i} !}, \quad y_{i}=0,1,2, \ldots
$$

The Poisson distribution is determined by the conditional mean parameter $\mu_{i}$, and its expected value is modelled as an exponential function to ensure non-negative predicted values for $y_{i}$ (Cameron and Trivedi 2013; Wooldridge 2013):

$$
\mu_{i}=E\left[y_{i} \mid x_{i}\right]=\exp \left(\beta x_{i}\right)
$$

Using longitudinal data provides the opportunity to account for unobserved time-invariant heterogeneity between individuals. The CRE model introduces the unobserved individual effect $a_{i}$ to the panel data Poisson model

$$
E\left[y_{i t} \mid x_{i t}, a_{i}\right]=a_{i} \exp \left(\beta x_{i t}\right)
$$

where $y_{i t}$ denotes the outcome variable for person $i$ at time $t, x_{i t}$ are the time-varying predictors with coefficients $\beta$, and $a_{i}$ is the unobserved effect. The random effects (RE) assumption is that $a_{i}$ is uncorrelated with the predictors $x_{i t}$. If this assumption is not met, the time-varying predictors $x_{i t}$ are endogenous because of omitted variables captured by $a_{i}$ and correlated with the time-varying predictors $x_{i t}$, leading to a biased estimation of $\beta$ (Hamaker and Muthén 2020; Wooldridge 2013). This assumption can be tested by including time-averaged values of time-varying predictors $\bar{x}_{i}$ to model the correlation between $a_{i}$ and $x_{i t}$. Assuming a linear relationship, $a_{i}$ is modelled as

$$
a_{i}=\exp \left(\gamma \bar{x}_{i}+r_{i}\right)
$$

where $\bar{x}_{i}$ is the time average of the time-varying exogenous variables with coefficients $\gamma$ and $r_{i}$ denotes unobserved heterogeneity that is assumed to be uncorrelated with $x_{i t}$ (Cameron and Trivedi 2013). Substituting equation 4 into equation 3 gives

$$
E\left[y_{i t} \mid x_{i t}, a_{i}\right]=\exp \left(\beta x_{i t}+\gamma \bar{x}_{i}+r_{i}\right)
$$

which is the CRE Poisson model (Cameron and Trivedi 2013). The estimate for $\gamma$, called the 'contextual effect', serves as a tool for testing whether CRE or RE assumptions are necessary. An estimate of a contextual effect that 
is not statistically significantly different from zero means that the RE assumption is sufficient, and in that case the $\mathrm{RE}$ approach delivers more efficient estimates of $\beta$ (Wooldridge 2013). We thus include the statistically significant contextual effects into our models (Schunck and Perales 2017). For the mediation analysis, we multiply the coefficients of paths between others donations, the mediators, and focal donor's donations (Coxe and MacKinnon 2010), and obtain standard errors via the delta method.

\section{Instrumental Variable Approach}

We use the number of invitations to donate blood per other inhabitant in the neighbourhood as an instrument for the donation attempts per other inhabitant. In the Netherlands, registered whole blood donors usually donate blood following a personal invitation from the blood bank. The instrument of invitations to others should meet the relevance and exogeneity requirements of an appropriate instrumental variable: it is strongly related to the donation behaviour of others, but, conditional on covariates (e.g., the individuals' invitations to donate), not directly related to the individuals' blood donation behaviour. It should therefore affect the individual's donations only through its effect on the donations by others. Once caveat to the exogeneity of the instrument might be that donors could receive invitations addressed to someone living in the same household. However, because invitations are personal and collected by the blood bank upon arrival at the location donation, we consider it unlikely that an individual donates based on the invitation to someone else unless the other person donates as well. The variable of invitations per inhabitant is calculated in a way analogous to the number of donation attempts per inhabitant, and based on data from the Donor Registry. To implement the instrumental variable approach in the CRE Poisson model, we follow the control function approach described in Lin and Wooldridge (2019). In the first stage, the donations per inhabitant are regressed on the number of invitations per inhabitant and covariates in a fixedeffects regression. In the second stage, we re-estimate the Poisson CRE while including the residuals from the first stage (the control function), and obtain standard errors via bootstrapping based on 5,000 replications (Cameron \& Trivedi, 2013, p. 56; Lin \& Wooldridge, 2019).

\section{Results}

We first present the results on social contagion of blood donation behaviour, and exploratory analyses on between whom social contagion occurs. Subsequently, we present the results on the potential mediating mechanisms of normative and informational social influence. 


\subsection{Social Contagion Increases Repeated Blood Donations}

In Hypothesis 1 we stated that individuals are more likely to repeatedly donate if others do so as well. Table 3 shows the results for the regression of individuals' donation attempts on the donation attempts of others and covariates. From Model 1 in Table 3 we can see that a one-unit increase in the number of donations per inhabitant is estimated to increase the number of an individual's donations by about $11 \%(b=0.108, p=0.013)$. This estimate does not substantially change with the inclusion of the potential mediators (Model 2) and further covariates (Model 3). The left-hand panel of Figure 3 visualizes this effect. It indicates that an increase in the donation attempts per inhabitant from 0 to 1 would increase the individual's donations from about 3.2 donations to about 3.5 donations.

The results from the instrumental variable approach support our main finding. The coefficient for donations by others is positive and significant $(b=0.227, p=0.011)$, and the coefficient of the residuals included from the first stage (the control function) indicates that endogeneity with regard to time-varying unobservables is not a major concern $(b=-0.209 p=0.074)^{4}$. Next, following Benjamini and Hochberg (1995), we adjust for multiple hypothesis testing of our six hypothesis (including the mediated relationships tested below) to control for the false discovery rate (FDR). This reduces the significance threshold for $\mathrm{H} 1$ to $\mathrm{p}<0.008$, which the result for $\mathrm{H} 1$ does not meet. After excluding potential outliers (see Supplementary Material S1.2 for details) the estimate for the effect of the donations of others remains similar but is no longer statistically significant $(b=0.093, p=0.091)$. In conclusion, the result for $\mathrm{H} 1$ seems to be robust with regard to potential time-constant and time-varying unobservables, but the estimated effect is small and therefore sensitive to the control of the FDR and the exclusion of potential outliers.

\subsubsection{Social Contagion Between Whom?}

Based on the participants' information about their 'donor network' (see Figure 4), we can explore between whom social contagion within postcodes might operate.

Our exploratory analysis shows a significant interaction effect between the main effect of donations made by others in the same postcode and having a partner who is also a blood donor (Table 4). The effect of social contagion is much stronger for those individuals that have a partner who is also a donor, as shown in the right-hand panel of Figure 3. Re-estimating Model 3 among the subsample of donors with a donor partner suggests that a one-unit increase in the number of donations per inhabitant increases the number of the individuals' donations by about $35 \%(b=0.350, p<0.001)$. Social contagion within neighbourhoods seems to be mostly driven by social contagion within donor couples.

\footnotetext{
${ }^{4}$ Among donors living alone, this effect is negative and no longer statistically significant $(b=-0.12, p=0.61)$. This is likely because most donors connected to influential other donors (e.g., their partner) are excluded.
} 
Table 3 CRE Poisson regression of individuals' blood donation attempts on donation attempts per inhabitant and mediators, and linear CRE regression of mediators on donation attempts per inhabitant

\begin{tabular}{|c|c|c|c|c|c|c|}
\hline & \multicolumn{2}{|c|}{ (1) } & \multicolumn{2}{|c|}{ (2) } & \multicolumn{2}{|c|}{ (3) } \\
\hline & Coef. & S.E. & Coef. & S.E. & Coef. & S.E. \\
\hline \multicolumn{7}{|l|}{ Individuals' donation attempts } \\
\hline Donation attempts per inhab. & $0.108^{*}$ & $(0.044)$ & $0.102^{*}$ & $(0.043)$ & $0.105^{*}$ & $(0.043)$ \\
\hline Male & $0.480^{* * *}$ & $(0.026)$ & $0.474^{* * *}$ & $(0.026)$ & $0.465^{* * *}$ & $(0.026)$ \\
\hline Income & $-0.040^{* * *}$ & $(0.008)$ & $-0.022^{* *}$ & $(0.008)$ & $-0.026^{* *}$ & $(0.008)$ \\
\hline Age & $-0.020^{* * *}$ & $(0.002)$ & $-0.021^{* * *}$ & $(0.002)$ & $-0.021^{* * *}$ & $(0.002)$ \\
\hline Having children & $-0.115^{* * *}$ & $(0.033)$ & $-0.107^{* * *}$ & $(0.032)$ & $-0.109^{* * *}$ & $(0.032)$ \\
\hline $\ln$ (working hours+1) & $-0.021^{* *}$ & $(0.006)$ & $-0.019 * *$ & $(0.006)$ & $-0.020^{* *}$ & $(0.006)$ \\
\hline Previous donations & $-0.007^{* * *}$ & $(0.001)$ & $-0.008^{* * *}$ & $(0.001)$ & $-0.008^{* * *}$ & $(0.001)$ \\
\hline $\ln$ (Individuals' invitations +1 ) & $0.674^{* * *}$ & $(0.014)$ & $0.674^{* * *}$ & $(0.014)$ & $0.677^{* * *}$ & $(0.014)$ \\
\hline Permanently deferred & $-0.446^{* * *}$ & $(0.035)$ & $-0.447^{* * *}$ & $(0.035)$ & $-0.452^{* * *}$ & $(0.035)$ \\
\hline Subjective norms & & & 0.021 & $(0.011)$ & 0.016 & $(0.011)$ \\
\hline Self-identity & & & $0.115^{* * *}$ & $(0.018)$ & 0.024 & $(0.025)$ \\
\hline Moral norms & & & $-0.088^{* * *}$ & $(0.013)$ & $-0.030^{*}$ & $(0.015)$ \\
\hline Awareness of need & & & $0.050^{* * *}$ & $(0.012)$ & $0.055^{* * *}$ & $(0.015)$ \\
\hline Cognitive attitudes & & & 0.012 & $(0.009)$ & -0.001 & $(0.009)$ \\
\hline Generalized social trust & & & & & 0.016 & $(0.014)$ \\
\hline Self-efficacy & & & & & $0.038^{* *}$ & $(0.013)$ \\
\hline Altruism & & & & & -0.016 & $(0.012)$ \\
\hline Affective attitudes & & & & & 0.012 & $(0.010)$ \\
\hline Constant & $-1.087^{* * *}$ & $(0.069)$ & $-0.998^{* * *}$ & $(0.069)$ & $-0.963^{* * *}$ & $(0.069)$ \\
\hline \multicolumn{7}{|l|}{ Subjective norms } \\
\hline Donation attempts per inhab. & & & & & $0.063^{*}$ & $(0.032)$ \\
\hline Constant & & & & & 0.001 & $(0.008)$ \\
\hline \multicolumn{7}{|l|}{ Self-identity } \\
\hline Donation attempts per inhab. & & & & & 0.043 & $(0.029)$ \\
\hline Constant & & & & & 0.001 & $(0.008)$ \\
\hline \multicolumn{7}{|l|}{ Moral norms } \\
\hline Donation attempts per inhab. & & & & & 0.030 & $(0.029)$ \\
\hline Constant & & & & & 0.003 & $(0.008)$ \\
\hline \multicolumn{7}{|l|}{ Awareness of need } \\
\hline Donation attempts per inhab. & & & & & -0.004 & $(0.034)$ \\
\hline Constant & & & & & -0.007 & $(0.008)$ \\
\hline \multicolumn{7}{|l|}{ Cognitive attitudes } \\
\hline Donation attempts per inhab. & & & & & $0.072^{*}$ & $(0.030)$ \\
\hline Constant & & & & & 0.000 & $(0.007)$ \\
\hline$N$ & \multicolumn{2}{|c|}{24,552} & \multicolumn{2}{|c|}{24,552} & \multicolumn{2}{|c|}{24,552} \\
\hline AIC & \multirow{2}{*}{\multicolumn{2}{|c|}{$\begin{array}{l}106,877.1 \\
106,998.8\end{array}$}} & \multicolumn{2}{|c|}{$106,582.9$} & \multicolumn{2}{|c|}{$418,945.5$} \\
\hline BIC & & & 106,7 & 3.2 & 419,3 & 1.4 \\
\hline
\end{tabular}

Notes: Coefficients can be interpreted as semi-elasticities, meaning that the coefficient multiplied by 100 approximates the percentage change in the outcome for a one-unit change in the independent variable. Coefficients for log-transformed variables are elasticities, where the coefficient indicates the percentage change in the outcome for a $1 \%$ change in the independent variable. Statistically significant contextual effects are included in the regressions with individuals' donation attempts as DV, and in the regressions with the mediating constructs as DV. Estimates for all contextual effects are shown in Table S4. Heteroskedasticity-robust standard errors in parentheses.

${ }^{*} p<0.05,{ }^{* *} p<0.01,{ }^{* * *} p<0.001$ 

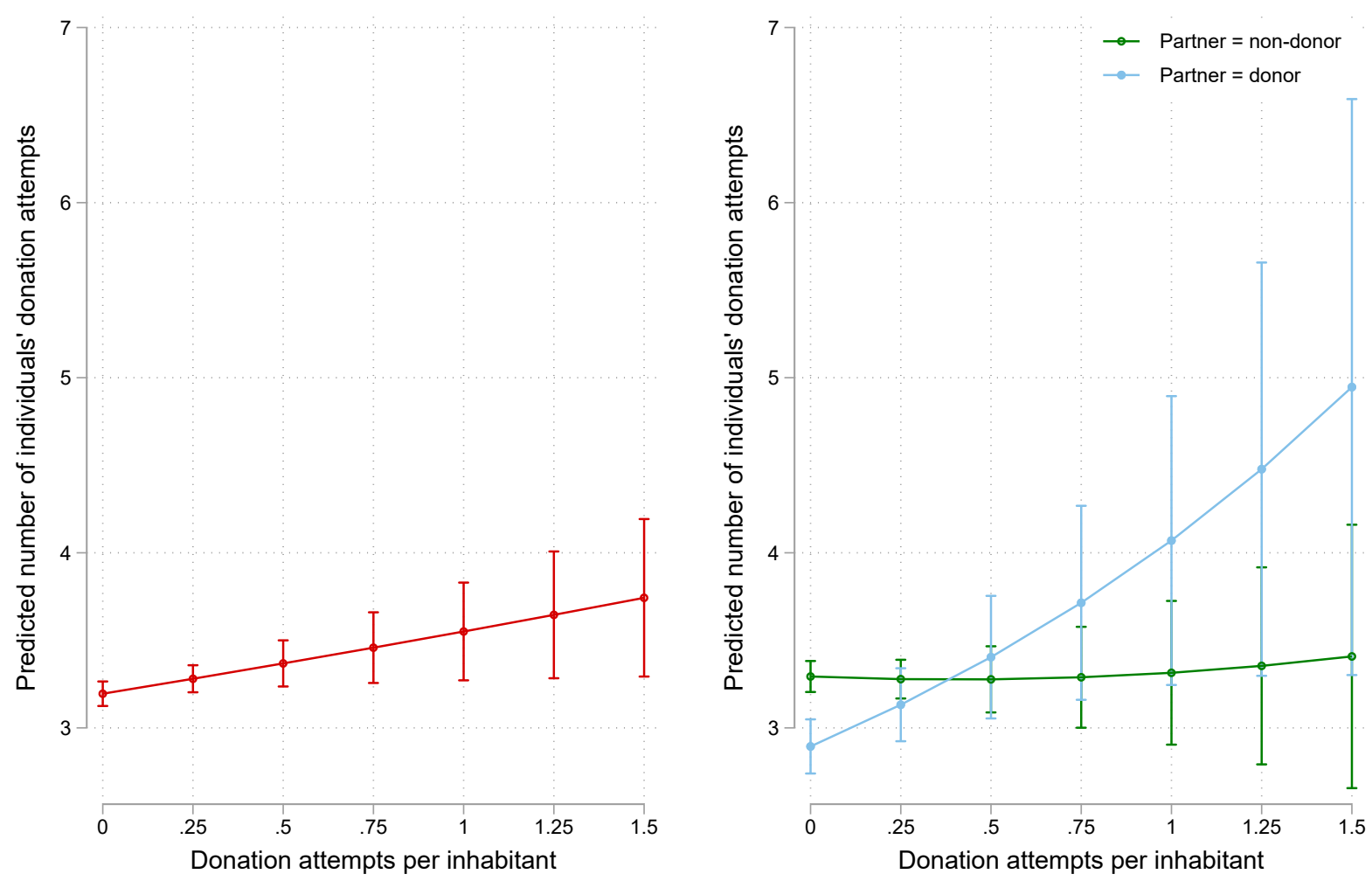

Figure 3 Predicted number of individuals' blood donation attempts with 95\% CIs derived from model 3 in Table 3. Left: Predicted number of individuals' blood donation attempts by number of donations per inhabitant. Right: Predicted number of individuals' blood donation attempts by number of donations per inhabitant and by having a partner that is a blood donor or not. Predictions are marginal with respect to the individual-specific random effect.

Table 4 Interaction effects of donations by others with donors in network

\begin{tabular}{lcc}
\hline & Coef. & S.E. \\
\hline Interaction of donations by others with: & & \\
Partner = donor & $0.335^{* *}$ & $(0.115)$ \\
Donors among family members & -0.086 & $(0.105)$ \\
Donors among friends & -0.184 & $(0.110)$ \\
Knows any other donors & 0.070 & $(0.199)$ \\
Not living alone & 0.313 & $(0.180)$ \\
Novice & 0.178 & $(0.168)$ \\
\hline
\end{tabular}

Notes: Results for interaction terms of donations per inhabitant with dummy variables given in the table. Heteroskedasticity-robust standard errors in parentheses.

${ }^{*} p<0.05,{ }^{* *} p<0.01,{ }^{* * *} p<0.001$ 


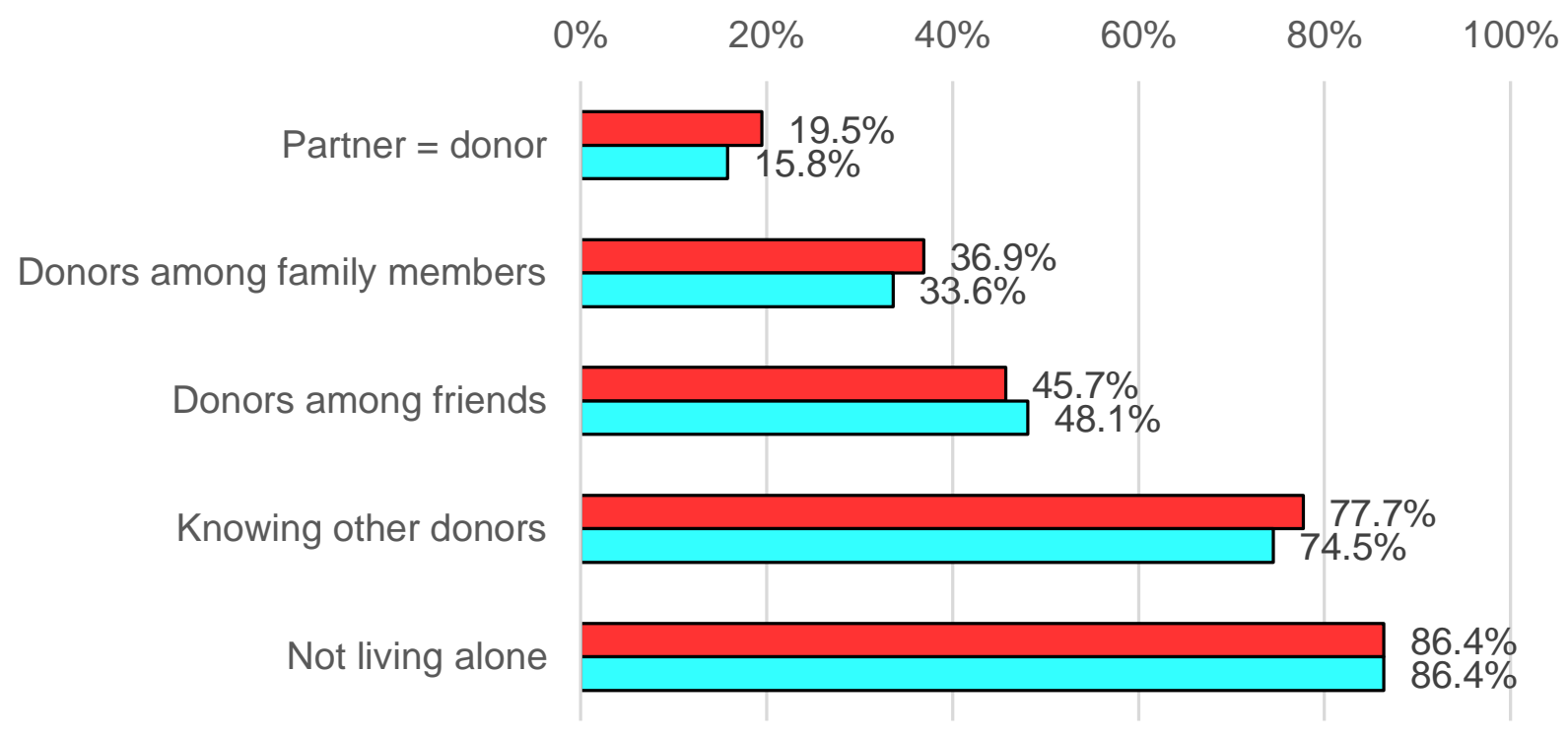

at1 at2

Figure 4 Donors within the focal donor's social network.

Notes: Participants were asked 'Are there people among your direct acquaintances who are blood donors?' and could select several of the first three response options given above. Knowing other donors is a dummy that captures whether 'yes' was answered to any of these options. 'Not living alone' is a dummy that indicates whether donors live alone (or with children), or together with others, including potential donors. 


\subsection{No Evidence that Normative and Informational Social Influence Mediate Social Conta- gion}

Table 3 also displays the results for the hypothesized mediated relationships (H2-H6). The lower half of Table 3 shows how individuals attitudes towards blood donations change with the donation behaviour of others. Each of the potential mediators is displayed in its own row, which shows the results from a linear CRE regression of the mediator on donations by others. In line with our hypotheses, individuals' subjective norms and cognitive attitudes are positively and statistically significantly related to the donation behaviour of others. For each one-unit increase in the number of donations per inhabitant, individuals' subjective norms are estimated to increase by about .06 units (the subjective norms measure has a range of 3.81). For each one-unit increase in the number of donations per inhabitant, individuals' cognitive attitudes are estimated to increase by about .07 units (the cognitive attitudes measure has a range of 8.53). The remaining mediators, however, are not statistically significantly related to the donation behaviour of others.

The upper half of Table 3 shows to what extent the potential mediators affect individuals' whole blood donation attempts. Model 3 shows that a one-unit increase in individuals' moral norms about blood donations (whose measure has a range of 4.41) is estimated to decrease the number of individuals' donations by about $3 \%$. A oneunit increase in individuals' awareness of need for blood donations (which has a range of 5.99) is related to a $5.5 \%$ increase in the number of individuals' donations. In Model 3, changes in individuals subjective norms, selfidentity, and cognitive attitudes are not statistically significantly associated with changes in individuals donation behaviour. Because of the strong association between self-efficacy and self-identity and moral norms, we included included the covariates added in Model 3 stepwise S6. This shows that the effects of self-identity and moral norms are particularly sensitive to the inclusion of self-efficacy as a covariate, highlighting that the within-person effects of individuals' self-efficacy, self-identity, and moral norms are highly related.

Finally, we test for evidence for the mediated relationships. From the test for the significance of the indirect effects (Figure 5) we see that none of them are statistically significantly different from 0. Hypotheses 2-6 about normative and informational social influence underlying social contagion are therefore not supported. 


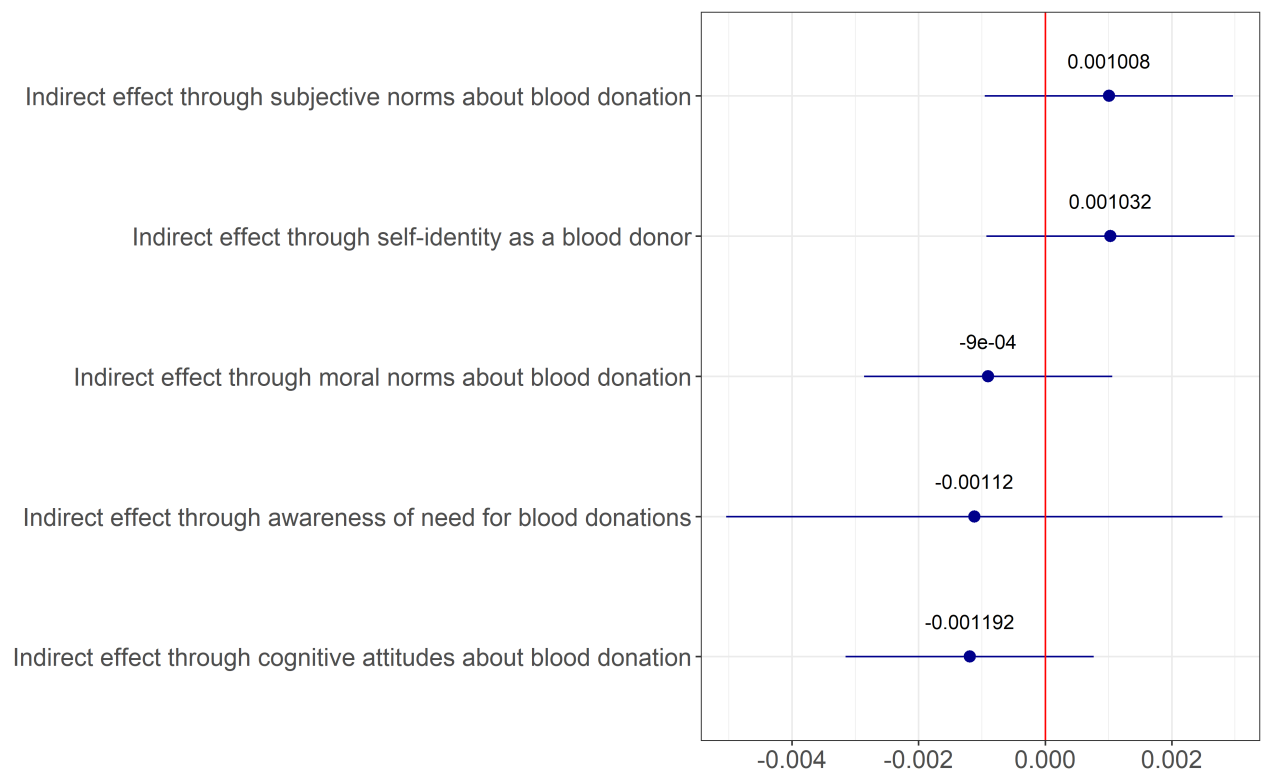

Figure 5 Results of the mediation analysis.

Notes: Estimates are based on coefficients of Model 3 (see Table 3). Standard errors obtained via the delta method.

\section{Discussion and Conclusions}

This study has analysed how social contagion affects whole blood donations in the Netherlands, a public good that is critically dependent on individuals' repeated prosocial behaviour. While extensive theoretical and experimental work provided the insight that social contagion can contribute to sustaining collective action over time, this insight had not yet been integrated into largely individual-centred theoretical and empirical work on repeated real-world prosocial behaviour. We linked these two strands of the literature by providing a theoretical framework of social contagion through social influence. The goal of the empirical part of this study was twofold: firstly, to assess to what extent social contagion contributes to sustaining repeated blood donations; and secondly, to assess whether social contagion is mediated by normative and informational social influence.

Regarding the first aim, our results showed a small social contagion effect: a one-unit increase in the number of donations per inhabitant of the focal donor's neighbourhood (e.g., all others donating twice instead of once) is associated with a $11 \%$ increase in the number of whole blood donation attempts by individuals over the course of a three-year period. This result is robust with regard to time-constant and time-varying unobservables, but the estimated effect is small and therefore sensitive to the control of the FDR and the exclusion of potential outliers. This small effect might reflect that the visibility of blood donation behaviour is generally low. An individuals neighbours do not necessarily know about the focal donor's donation behaviour. This is also in line with our exploratory analysis showing that the effect can likely be attributed to social contagion among donor-couples. In the subsample of donors with a partner who is also a donor, a one-unit increase in the number of donations per inhabitant is 
associated with a $35 \%$ increase in the number of whole blood donation attempts by the individual.

Regarding the second aim, we did not find evidence that normative or informational social influences underly social contagion in prosocial behaviour. That is, social contagion in repeated blood donation behaviour does not seem to work through affecting blood donors' subjective norms, self-identity, moral norms, awareness of need, or cognitive attitudes about blood donations. These beliefs and attitudes that are central to theories of individuals donation behaviour do not seem to be derived from others donation behaviour; that is, at least not in the relatively short term of 4 years and among adults that are already blood donors. In addition, many of the constructs thought to capture attitudinal influences on intentions to donate blood, such as subjective norms and cognitive attitudes, do surprisingly little in explaining repeated blood donation behaviour over time, as indicated by small and insignificant within-person effects. Two exceptions are the effect of moral norms about blood donation, and awareness of need for blood donations. Regarding moral norms the results indicate that an increased perception of a moral obligation to donate blood is associated with a decrease rather than an increase in blood donations over time, when also taking individuals' self-identity and self-efficacy into account. Self-identity, a construct thought particularly important to donor retention, did predict repeated blood donations, but was strongly related and ultimately overpowered by the effect of donors' self-efficacy. Increasing awareness of need for blood donations was associated with an increase in the number of donors' whole blood donations. This is particularly interesting since the effect of donors' awareness of the need for blood donations has rarely been considered in quantitative analyses of blood donation behaviour. Increasing the awareness of need for blood donations among existing donors might thus contribute to sustaining their repeated blood donation behaviour over time, but reverse causality should be ruled out in future studies. In sum, our results do not provide evidence that social contagion within neighbourhoods works through normative or informational social influence. Instead, the behaviour of others seems to exert an independent influence on repeated prosocial behaviour, and it remains a challenge to identify the mechanisms through which social contagion in prosocial behaviour works. One explanation could be that social contagion is based on stable social preferences, such as inequality aversion or generalized reciprocity (Fischbacher, Gächter, and Fehr 2001; Gächter, Nosenzo, and Sefton 2013; Nowak 2006), which do not need to change over time in order for social contagion to work. Another explanation might be that donations by others serve as a descriptive norm that simply conveys what other people do, but does not change individuals' beliefs and attitudes towards the behaviour.

\section{Limitations and Directions for Future Research}

A clear limitation of our study is the indirect approach to identifying potentially relevant others via geographical proximity to the donors surveyed. While our geographical measure is very small-scale and thus includes only individuals' cohabitants and direct neighbours, it does not capture individuals' relations to family members, friends, 
and colleagues who might be socially but not geographically close to our focal donors. This limitation provides an important insight for future studies: even with the use of very small-scale geographical data, a large sample, and behavioural data based on register data rather than self-reports, our study reveals only very small social contagion effects, which our exploratory analysis further attributes to donor couples. Contemporaneous similarities in behaviour within neighbourhoods should therefore not simply be attributed to processes of social influence. An important next step for future work would therefore be to reassess social contagion based on longitudinal social network data. Another promising avenue for future research would be to uncover heterogeneity in how individuals are affected by the donation behaviour of others. While our study has assumed that all individuals are positively affected by the donation behaviour of others, there might be donors who donate particularly because others do not (Ferguson and Lawrence 2016; Oliver 1984).

\section{Implications}

Two major implications follow from our results. The first concerns theories of repeated prosocial behaviour. Our results show that the presumed importance of social contagion for the maintenance of prosocial behaviour in the literature on collective action does, to some extent, translate to a better understanding of repeated real-world prosocial behaviour; social contagion can contribute to sustaining individuals' repeated prosocial behaviour over time. Therefore, our results are not consistent with the 'pure altruism' model of prosocial behaviour, where individuals aim for an overall level of public good provision and their contributions are thus crowded out by the prosocial behaviour of others. We show that, on average, blood donations by individuals and others complement rather than substitute one another. Theoretical models aimed at explaining repeated prosocial behaviour would benefit from incorporating this insight. In addition, the effect of social contagion is not mediated by attitudinal constructs included in current theoretical models of repeated prosocial behaviour; it should be included as an independent predictor of individuals' repeated prosocial behaviour. Furthermore, our finding that social contagion is likely taking place among donor couples is in line with other studies showing that social proximity moderates the effect of social influences on blood donation behaviour (Goette and Tripodi 2022).

The second implication relates to recruitment and retention efforts of volunteering organizations and blood banks in particular. Bruhin et al. (2020) have previously shown that invitations to donate are more effective if they are aimed at donor couples rather than isolated donors. Our results similarly show that blood banks' retention efforts are likely to be more successful if they are targeted at groups and particularly donor couples, because they reinforce each other's donation behaviour over time. Such interventions could make the behaviour of other donors more salient, e.g., by mentioning how often others usually donate. Our results further imply that such interventions should not target spatially defined communities, but rather important members of donors' social networks. 


\section{Acknowledgements}

We thank Femmeke Prinsze for her effort in collecting the blood donor data from the Dutch donor registry, and René Bekkers, Adrian Bruhin, Eamonn Ferguson, Caroline Graf, Elisabeth Naderlinger, Tijs van den Broek, Claire van Teunenbroek, and Beate Völker for valuable remarks on earlier versions of the manuscript.

\section{References}

Ajzen, Icek (1991). “The theory of planned behavior”. In: Organizational Behavior and Human Decision Processes 50.2, pp. 179-211.

Andreoni, James (1990). "Impure Altruism and Donations to Public Goods: A Theory of Warm-Glow Giving”. In: The Economic Journal 100.401, pp. 464-477.

Armitage, Christopher J. and Mark Conner (Dec. 2001a). "Efficacy of the Theory of Planned Behaviour: a metaanalytic review”. eng. In: The British Journal of Social Psychology 40.Pt 4, pp. 471-499.

- (2001b). “Social Cognitive Determinants of Blood Donation”. In: Journal of Applied Social Psychology 31.7, pp. 1431-1457.

Bagozzi, Richard P. and Youjae Yi (1988). "On the evaluation of structural equation models". In: Journal of the Academy of Marketing Science 16.1, pp. 74-94.

Baldwin, Scott A. (2019). Psychological statistics and psychometrics using Stata. First edition. College Station, Texas: Stata Press. xxii, 454.

Becker, Gary S. (Nov. 1, 1974). “A Theory of Social Interactions”. In: Journal of Political Economy 82.6, pp. 10631093.

Bednall, Timothy C. et al. (2013). "A systematic review and meta-analysis of antecedents of blood donation behavior and intentions". In: "Social Science \& Medicine" 96, pp. 86-94.

Bekkers, René (2010). "Who gives what and when? A scenario study of intentions to give time and money". In: Social Science Research 39.3, pp. 369-381.

Bekkers, René and Pamala Wiepking (2011). “A Literature Review of Empirical Studies of Philanthropy: Eight Mechanisms That Drive Charitable Giving”. In: Nonprofit and Voluntary Sector Quarterly 40.5, pp. 924-973.

Benjamini, Yoav and Yosef Hochberg (1995). "Controlling the False Discovery Rate: A Practical and Powerful Approach to Multiple Testing”. In: Journal of the Royal Statistical Society. Series B (Methodological) 57.1, pp. 289300.

Bollen, Kenneth A. and Mark D. Noble (2011). "Structural equation models and the quantification of behavior". In: Proceedings of the National Academy of Sciences 108 (Supplement 3), pp. 15639-15646.

Bruhin, Adrian et al. (2020). "Spillovers of prosocial motivation: Evidence from an intervention study on blood donors". In: Journal of Health Economics 70, p. 102244.

Callero, Peter L. (1985). “Role-Identity Salience”. In: Social Psychology Quarterly 48.3, pp. 203-215. 
Cameron, A. Colin and Pravin K. Trivedi (2013). Regression Analysis of Count Data. 2nd ed. Econometric Society Monographs. Cambridge: Cambridge University Press.

Centraal Bureau voor de Statistiek (CBS) (2020). Kerncijfers per postcode. Key figures per postcode. URL: https : //www.cbs.nl/nl-nl/dossier/nederland-regionaal/geografische-data/gegevens-per-postcode (visited on 09/16/2020).

Charng, Hong-Wen, Jane Allyn Piliavin, and Peter L. Callero (1988). "Role Identity and Reasoned Action in the Prediction of Repeated Behavior”. In: Social Psychology Quarterly 51.4, pp. 303-317.

Chaudhuri, Ananish (2011). "Sustaining cooperation in laboratory public goods experiments: a selective survey of the literature". In: Experimental Economics 14.1, pp. 47-83.

Cialdini, Robert B. and Noah J. Goldstein (2004). “Social Influence: Compliance and Conformity”. In: Annual Review of Psychology 55.1, pp. 591-621.

Coxe, Stefany and David P. MacKinnon (2010). "Abstract: Mediation Analysis of Poisson Distributed Count Outcomes". In: Multivariate Behavioral Research 45.6, pp. 1022-1022.

Darley, John and Bibb Latane (Apr. 1968). "BYSTANDER INTERVENTION IN EMERGENCIES: DIFFUSION OF RESPONSIBILITY". In: Journal of Personality and Social Psychology 8.4, pp. 377-383.

Deutsch, Morton and Harold B. Gerard (1955). "A study of normative and informational social influences upon individual judgment”. In: The Journal of Abnormal and Social Psychology 51.3, pp. 629-636.

Dietz, Robert D. (Dec. 1, 2002). "The estimation of neighborhood effects in the social sciences: An interdisciplinary approach". In: Social Science Research 31.4, pp. 539-575.

Fehr, Ernst and Simon Gächter (2002). “Altruistic punishment in humans”. In: Nature 415, pp. 137-140.

Fehr, Ernst and Ivo Schurtenberger (2018). "Normative foundations of human cooperation”. In: Nature Human Behaviour 2.7, pp. 458-468.

Ferguson, Eamonn, Alexandra Hill, et al. (2020). "A typology of blood donor motivations". In: Transfusion 60.9, pp. 2010-2020.

Ferguson, Eamonn and Claire Lawrence (2016). "Blood donation and altruism: the mechanisms of altruism approach”. In: ISBT Science Series 11.S1, pp. 148-157.

Fischbacher, Urs and Simon Gächter (2010). "Social Preferences, Beliefs, and the Dynamics of Free Riding in Public Goods Experiments". In: American Economic Review 100.1, pp. 541-556.

Fischbacher, Urs, Simon Gächter, and Ernst Fehr (2001). "Are people conditionally cooperative? Evidence from a public goods experiment". In: Economics Letters 71.3, pp. 397-404.

Foss, Robert D. (1983). “Community Norms and Blood Donation”. In: Journal of Applied Social Psychology 13.4, pp. 281-290.

Frey, Bruno S. and Stephan Meier (2004). "Social Comparisons and Pro-social Behavior: Testing "Conditional Cooperation" in a Field Experiment”. In: American Economic Review 94.5, pp. 1717-1722.

Gächter, Simon, Daniele Nosenzo, and Martin Sefton (2013). "Peer Effects in Pro-Social Behavior: Social Norms or Social Preferences?" In: Journal of the European Economic Association 11.3, pp. 548-573. 
Galster, George C. (2012). “The Mechanism(s) of Neighbourhood Effects: Theory, Evidence, and Policy Implications". In: Neighbourhood Effects Research: New Perspectives. Ed. by Maarten van Ham et al. Dordrecht: Springer Netherlands, pp. 23-56.

Gintis, Herbert et al. (2003). “Explaining altruistic behavior in humans”. In: Evolution and Human Behavior 24.3, pp. 153-172.

Goette, Lorenz and Egon Tripodi (2022). Social Recognition: Experimental Evidence from Blood Donors. SSRN Scholarly Paper ID 3886951. Rochester, NY: Social Science Research Network.

Grube, Jean A. and Jane Allyn Piliavin (2000). "Role Identity, Organizational Experiences, and Volunteer Performance”. In: Personality and Social Psychology Bulletin 26.9, pp. 1108-1119.

Hamaker, Ellen L. and Bengt Muthén (2020). "The fixed versus random effects debate and how it relates to centering in multilevel modeling." In: Psychological Methods 25.3, pp. 365-379.

Healy, Kieran (2000). “Embedded Altruism: Blood Collection Regimes and the European Union's Donor Population". In: American Journal of Sociology 105.6, pp. 1633-1657.

Irwin, Kyle and Brent Simpson (Mar. 1, 2013). "Do Descriptive Norms Solve Social Dilemmas? Conformity and Contributions in Collective Action Groups". In: Social Forces 91.3, pp. 1057-1084.

Kline, Rex B. (2016). Principles and practice of structural equation modeling, 4th ed. Principles and practice of structural equation modeling, 4th ed. New York, NY, US: Guilford Press. xvii, 534.

Krupka, Erin L., Stephen Leider, and Ming Jiang (2016). "A Meeting of the Minds: Informal Agreements and Social Norms”. In: Management Science 63.6, pp. 1708-1729.

Krupka, Erin L. and Roberto A. Weber (2013). "Identifying Social Norms Using Coordination Games: Why Does Dictator Game Sharing Vary?" In: Journal of the European Economic Association 11.3, pp. 495-524.

Lin, Wei and Jeffrey M. Wooldridge (2019). "Testing and Correcting for Endogeneity in Nonlinear Unobserved Effects Models". In: Panel Data Econometrics. Ed. by Mike Tsionas. Academic Press, pp. 21-43.

Lindström, Björn et al. (2018). "The role of a 'common is moral' heuristic in the stability and change of moral norms". In: Journal of Experimental Psychology: General 147.2, pp. 228-242.

Manski, Charles F. (1993). “Identification of Endogenous Social Effects: The Reflection Problem”. In: The Review of Economic Studies 60.3, pp. 531-542.

Marwell, Gerald and Pamela Oliver (1993). The Critical Mass in Collective Action. Cambridge University Press.

Masser, Barbara M. et al. (2008). “The Psychology of Blood Donation: Current Research and Future Directions”. In: Transfusion Medicine Reviews 22.3, pp. 215-233.

Merz, Eva-Maria, Katja van den Hurk, and Wim de Kort (2017). "Organ Donation Registration and Decision-Making Among Current Blood Donors in the Netherlands”. In: Progress in Transplantation 27.3, pp. 266-272.

Nowak, Martin A. (Dec. 2006). "Five rules for the evolution of cooperation”. In: Science (New York, N.Y.) 314.5805, pp. 1560-1563.

Nowak, Martin A. and Karl Sigmund (2005). “Evolution of indirect reciprocity”. In: Nature 437.7063, pp. 1291-1298. 
Oliver, Pamela (1984). “"If You Don't Do it, Nobody Else Will": Active and Token Contributors to Local Collective Action”. In: American Sociological Review 49.5, pp. 601-610.

Omoto, Allen M. and Mark Snyder (2002). “Considerations of Community: The Context and Process of Volunteerism”. In: American Behavioral Scientist 45.5, pp. 846-867.

Petrović, Ana, David Manley, and Maarten van Ham (Aug. 28, 2019). "Freedom from the tyranny of neighbourhood: Rethinking sociospatial context effects”. In: Progress in Human Geography, p. 0309132519868767.

Piersma, Tjeerd W. et al. (2017). "Individual, contextual and network characteristics of blood donors and nondonors: a systematic review of recent literature”. In: Blood Transfusion = Trasfusione Del Sangue 15.5, pp. 382397.

Piliavin, Jane Allyn (1990). "Why do they give the gift of life? A review of research on blood donors since 1977". In: Transfusion 30.5, pp. 444-459.

Piliavin, Jane Allyn and Peter L. Callero (1991). Giving blood: The development of an altruistic identity. Giving blood: The development of an altruistic identity. Baltimore, MD, US: Johns Hopkins University Press.

Piliavin, Jane Allyn, Jean A. Grube, and Peter L. Callero (2002). "Role as Resource for Action in Public Service”. In: Journal of Social Issues 58.3, pp. 469-485.

Piliavin, Jane Allyn and Donald Libby (1986). “Personal Norms, Perceived Social Norms, and Blood Donation”. In: Humboldt Journal of Social Relations 13.1, pp. 159-194.

Rockwood, Nicholas J. (June 1, 2021). “Efficient Likelihood Estimation of Generalized Structural Equation Models with a Mix of Normal and Nonnormal Responses”. In: Psychometrika 86.2, pp. 642-667.

Sanquin (2020). Dutch Blood Donor Database (eProgesa). Amsterdam.

Schervish, Paul G. and John J. Havens (Sept. 1, 1997). “Social participation and charitable giving: A multivariate analysis”. In: Voluntas: International Journal of Voluntary and Nonprofit Organizations 8.3, pp. $235-260$.

Schunck, Reinhard and Francisco Perales (2017). "Within- and Between-cluster Effects in Generalized Linear Mixed Models: A Discussion of Approaches and the Xthybrid command:” in: The Stata Journal.

Simpson, Brent and Robb Willer (2015). "Beyond Altruism: Sociological Foundations of Cooperation and Prosocial Behavior”. In: Annual Review of Sociology 41.1, pp. 43-63.

Slonim, Robert, Carmen Wang, and Ellen Garbarino (May 2014). “The Market for Blood”. In: Journal of Economic Perspectives 28.2, pp. 177-96.

Sniehotta, Falko F., Justin Presseau, and Vera Araújo-Soares (Jan. 2, 2014). “Time to retire the theory of planned behaviour". In: Health Psychology Review 8.1, pp. 1-7.

Sparks, Paul and Carol A. Guthrie (1998). "Self-Identity and the Theory of Planned Behavior: A Useful Addition or an Unhelpful Artifice?1”. In: Journal of Applied Social Psychology 28.15, pp. 1393-1410.

StataCorp. (2016). Stata Structural Equation Modeling Reference Manual Release 16. College Station, TX.

- (2019). Stata Statistical Software: Release 16. College Station, TX.

Stets, Jan E. and Peter J. Burke (2000). “Identity Theory and Social Identity Theory”. In: Social Psychology Quarterly 63.3, pp. 224-237. 
Stryker, Sheldon and Peter J. Burke (2000). “The Past, Present, and Future of an Identity Theory”. In: Social Psychology Quarterly 63.4, pp. 284-297.

Sugden, Robert (1984). "Reciprocity: The Supply of Public Goods Through Voluntary Contributions”. In: The Economic Journal 94.376, pp. 772-787.

Thöni, Christian and Stefan Volk (2018). “Conditional cooperation: Review and refinement”. In: Economics Letters 171, pp. 37-40.

Timmer, Tiffany C. et al. (2019). "Donor InSight: characteristics and representativeness of a Dutch cohort study on blood and plasma donors". In: Vox Sanguinis 114.2, pp. 117-128.

Tsvetkova, Milena and Michael W. Macy (2014). “The Social Contagion of Generosity”. In: PLOS ONE 9.2, e87275.

Turner, Ralph H. (1978). “The Role and the Person”. In: American Journal of Sociology 84.1, pp. 1-23.

van Teunenbroek, Claire, René Bekkers, and Bianca Beersma (2020). "Look to Others Before You Leap: A Systematic Literature Review of Social Information Effects on Donation Amounts". In: Nonprofit and Voluntary Sector Quarterly 49.1, pp. 53-73.

Veldhuizen, Eleonore M., Karien Stronks, and Anton E. Kunst (July 2013). "Assessing Associations between SocioEconomic Environment and Self-Reported Health in Amsterdam Using Bespoke Environments". en. In: PLOS ONE 8.7, e68790.

Veldhuizen, Ingrid et al. (2011). "Exploring the dynamics of the theory of planned behavior in the context of blood donation: does donation experience make a difference?” In: Transfusion 51.11, pp. 2425-2437.

Vesterlund, Lise (2003). “The informational value of sequential fundraising”. In: Journal of Public Economics 87.3, pp. 627-657.

Weber, J. Mark and J. Keith Murnighan (2008). "Suckers or saviors? Consistent contributors in social dilemmas". In: Journal of Personality and Social Psychology 95.6, pp. 1340-1353.

White, Katherine M. et al. (2009). "Social influence in the theory of planned behaviour: The role of descriptive, injunctive, and in-group norms". In: British Journal of Social Psychology 48.1, pp. 135-158.

Wilson, John (2000). “Volunteering”. In: Annual Review of Sociology 26.1, pp. 215-240.

Wilson, John and Marc Musick (1997). “Who Cares? Toward an Integrated Theory of Volunteer Work”. In: American Sociological Review 62.5, pp. 694-713.

Wood, Wendy (2000). “Attitude Change: Persuasion and Social Influence”. In: Annual Review of Psychology 51.1, pp. 539-570.

Wooldridge, Jeffrey M. (2013). Introductory Econometrics: A Modern Approach. 5th ed. OH: South-Western Cengage Learning. 
S1 Supplementary Material for the manuscript "The Social Contagion of Blood Donations: Sustaining Repeated Prosocial Behaviour" 


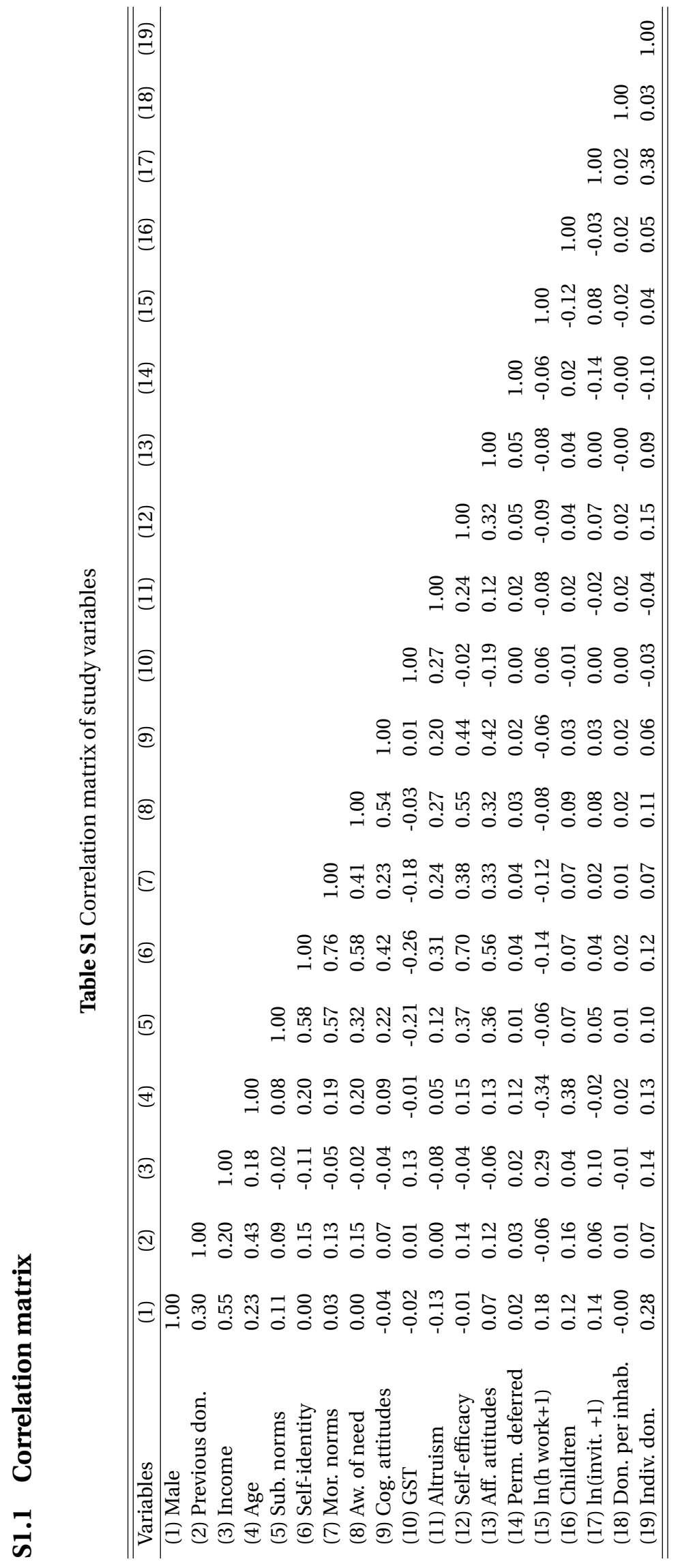




\section{S1.2 Outliers}

To check for the potential influence of outliers, we rerun our analysis (Model 3) excluding cases where the number of donations per inhabitant is more than three standard deviations from its mean. This leads to the exclusion of 528 observations.

Table S2 CRE Poisson regression of individuals' blood donation attempts on peers' donation attempts and covariates with outliers $3 \mathrm{SD}$ below and above the mean excluded

\begin{tabular}{lcc}
\hline & \multicolumn{2}{c}{$(1)$} \\
\hline Individuals' donation attempts & & \\
Donation attempts per inhab. & 0.093 & $(0.055)$ \\
Male & $0.470^{* * *}$ & $(0.026)$ \\
Income & $-0.027^{* *}$ & $(0.008)$ \\
Age & $-0.021^{* * *}$ & $(0.002)$ \\
Having children & $-0.106^{* *}$ & $(0.033)$ \\
ln(working hours+1) & $-0.019^{* *}$ & $(0.006)$ \\
Previous donations & $-0.008^{* * *}$ & $(0.001)$ \\
ln(Individuals' invitations +1$)$ & $0.675^{* * *}$ & $(0.014)$ \\
Permanently deferred & $-0.456^{* * *}$ & $(0.036)$ \\
Subjective norms & 0.017 & $(0.011)$ \\
Self-identity & 0.028 & $(0.026)$ \\
Moral norms & $-0.033^{* *}$ & $(0.015)$ \\
Awareness of need & $0.056^{* * *}$ & $(0.015)$ \\
Cognitive attitudes & -0.003 & $(0.009)$ \\
Generalized social trust & 0.015 & $(0.014)$ \\
Self-efficacy & $0.037^{* *}$ & $(0.013)$ \\
Altruism & -0.017 & $(0.012)$ \\
Affective attitudes & 0.014 & $(0.010)$ \\
Constant & $-0.952^{* * *}$ & $(0.069)$ \\
\hline$N$ & 24,137 & \\
\hline Standard errors in parentheses & & \\
${ }^{*} p<0.05,{ }^{* *} p<0.01,{ }^{* * *} p<0.001$ & & \\
& &
\end{tabular}

\section{S1.3 Assumption checks}

\section{Linearity}

To assess the linearity assumption that $\ln \left(y_{i}\right)$ is a linear function of the predictors, we plot the natural logarithm of the observed counts of individuals' donation attempts +1 against the predictors $x_{i t}$, as depicted in Figures S1 and S2. Individuals' invitations to donate and individuals' working hours were log-transformed to better meet the linearity assumption. 

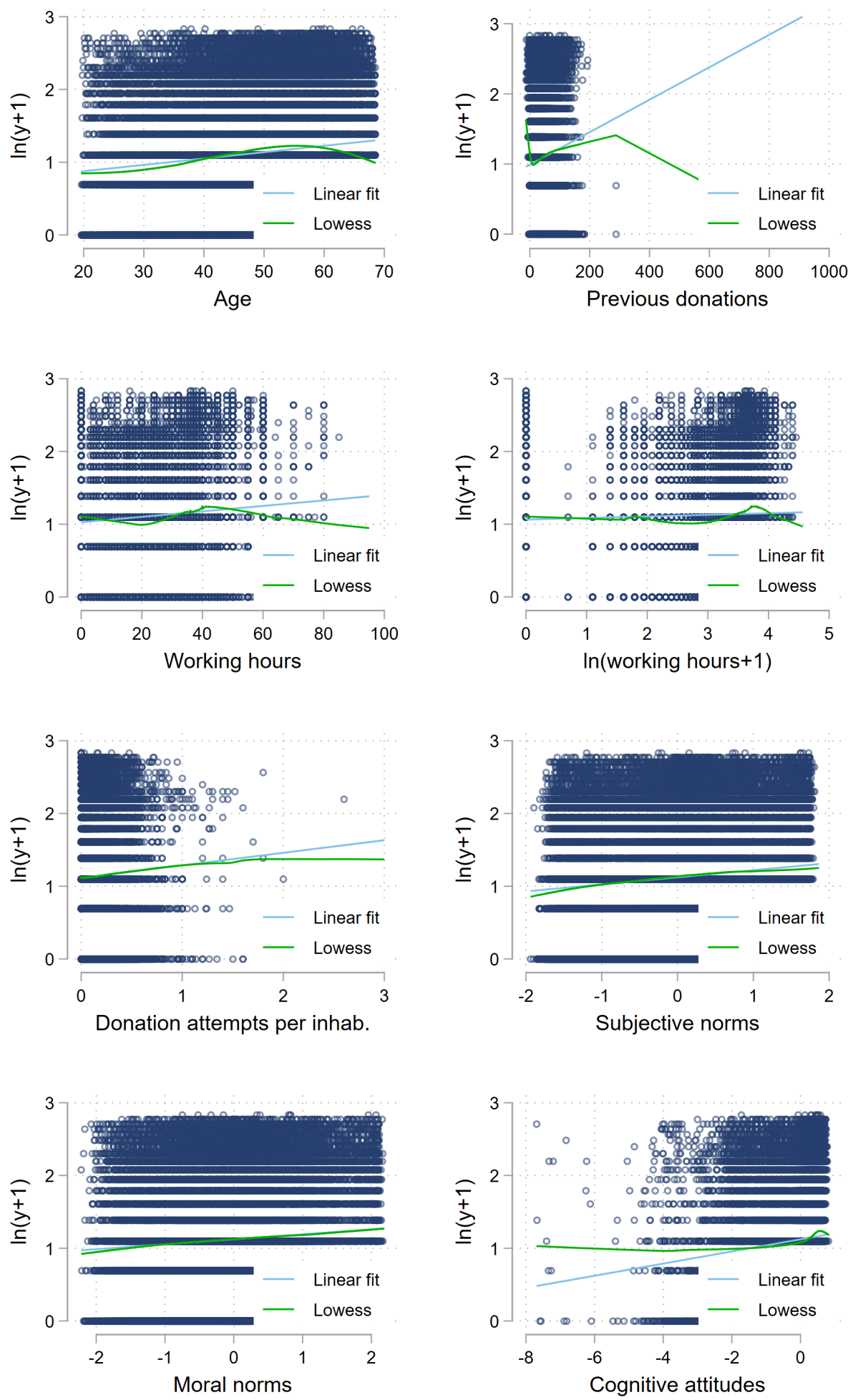

Figure S1 Assessing the linearity assumption for the independent variables age, individuals' previous donations, working hours, peers' donation attempts, subjective norms about blood donations, moral norms about blood donations, and cognitive attitudes about blood donations, which are used in the structural model. 

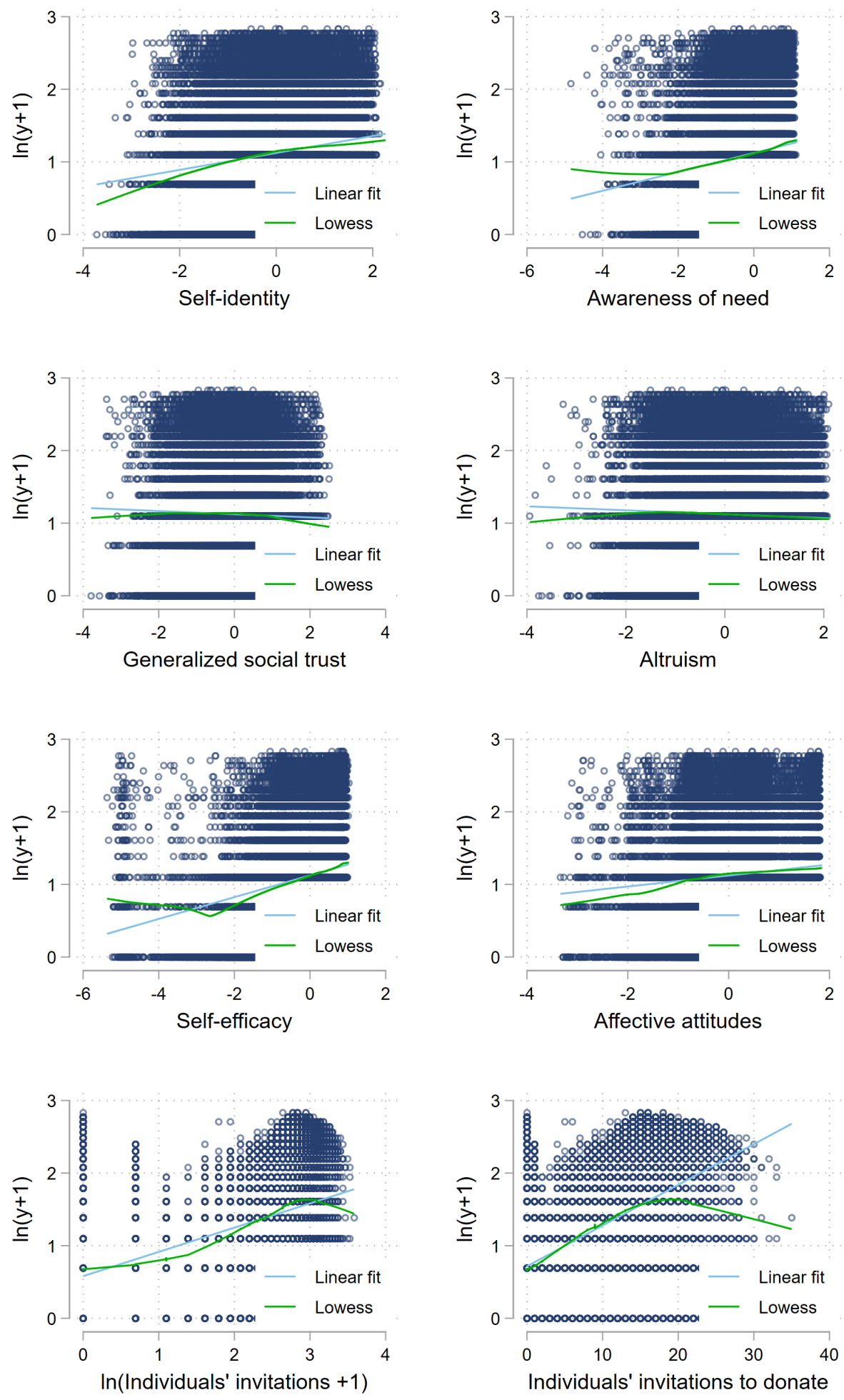

Figure S2 Assessing the linearity assumption for the independent variables self-identity, awareness of need, generalized social trust (GST), altruism, self-efficacy, affective attitudes, and individuals' invitations to donate, which are used in the structural model. 


\section{Fit of the Poisson distribution}

The Poisson model assumes equidispersion, referring to equality of the conditional variance $V$ and the conditional mean: $V\left[y_{i t} \mid x_{i t}, a_{i}\right]=\mu_{i t}$. The hanging rootogram (Buis 2011) of the number of donation attempts by individuals in Figure S3 shows that overdispersion might be a concern in our data. The rootogram 'hangs' a histogram from the theoretical Poisson distribution. The deviations of the 'spikes' in the histogram from the zero line thus indicate deviations from the theoretical distribution. The wave-like deviations from the Poisson distribution we observe in Figure S3 indicate unconditional overdispersion: there are more small counts (zeros) and large counts than a Poisson distribution with mean 3.58 (the sample mean of individuals' donation attempts) would predict, while there are fewer observed counts around the mean. Considerable overdispersion is also suggested by a comparison of the sample variance with the sample mean, with the sample variance (15.88) being 4.44 times the sample mean (3.58).

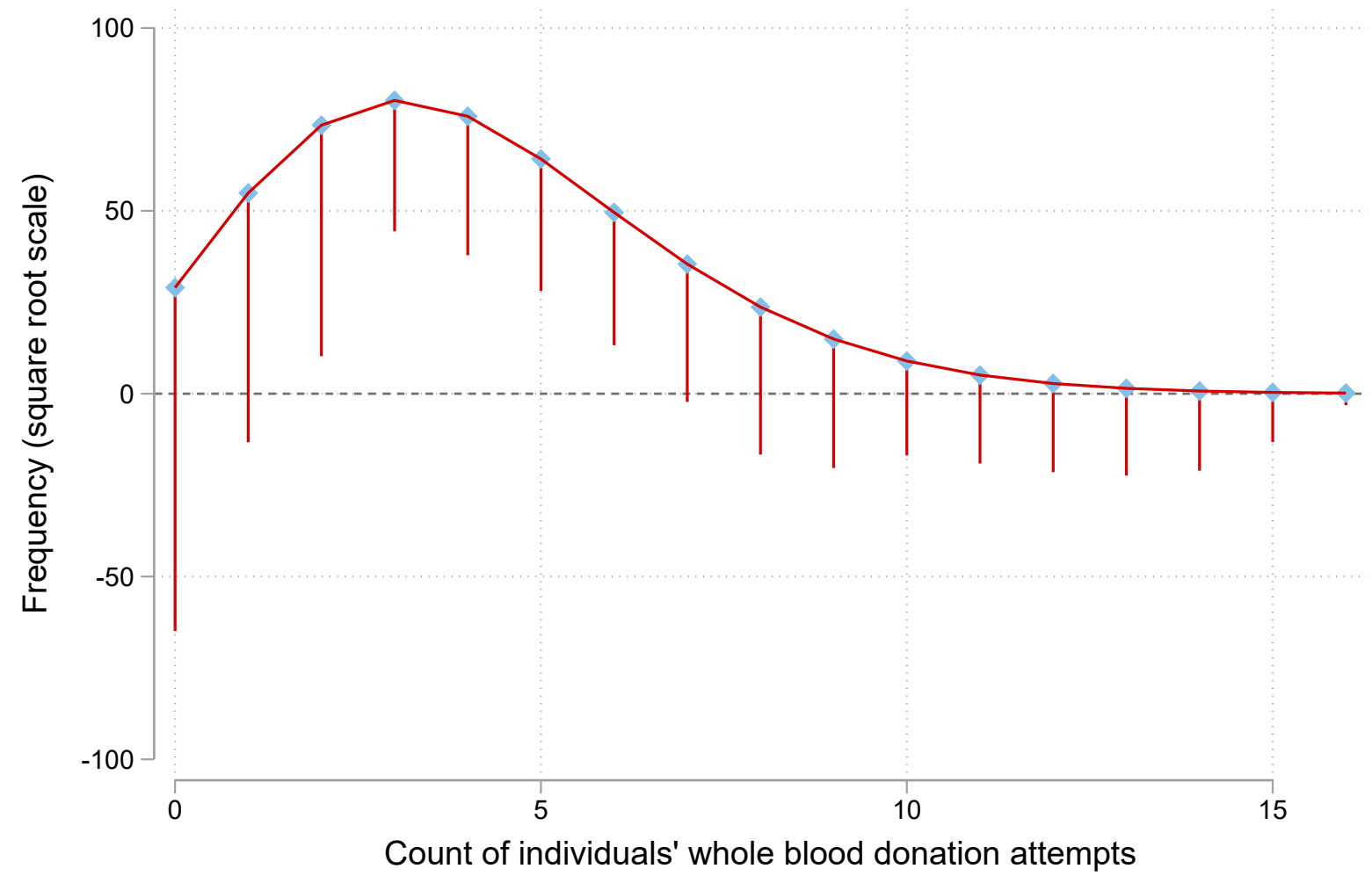

Figure S3 Hanging rootogram comparing the observed counts to a theoretical Poisson distribution.

To test for potential remaining overdispersion after the inclusion of the regressors and the individual-specific effect $a_{i}$, we compare the Poisson model to the 'NB2 model' (Cameron and Trivedi 2013). The latter specifies the variance as $V\left[y_{i t} \mid x_{i t}, a_{i}\right]=\mu_{i t}+\left(\mu_{i t}\right)^{2} \alpha$, and thus allows for additional dispersion in comparison to the Poisson 
model. With a dispersion parameter $\alpha$ of zero, the NB2 model reduces to the Poisson model. Table S3 shows that there is no remaining overdispersion after the inclusion of regressors and the individual-specific random effect: after ten iterations, the dispersion parameter $\alpha$ is estimated to be essentially zero, and estimation fails to converge because alpha is defined to be non-zero. Hence, we apply the Poisson model in our analyses.

Table S3 Comparison of Poisson with NB2 Model

\begin{tabular}{|c|c|c|c|c|c|c|c|c|}
\hline & \multicolumn{2}{|c|}{ Poisson (1) } & \multicolumn{2}{|c|}{ NB2 (1) } & \multicolumn{2}{|c|}{ Poisson (2) } & \multicolumn{2}{|c|}{ NB2 (2) } \\
\hline \multicolumn{9}{|c|}{ Individuals' donation attempts } \\
\hline Don. att. per inhab. & $0.102^{*}$ & $(0.043)$ & $0.102^{*}$ & $(0.043)$ & $0.105^{*}$ & $(0.043)$ & $0.106^{*}$ & $(0.043)$ \\
\hline Male & $0.474^{* * *}$ & $(0.026)$ & $0.474^{* * *}$ & $(0.026)$ & $0.465^{* * *}$ & $(0.026)$ & $0.465^{* * *}$ & $(0.026)$ \\
\hline Income & $-0.022^{* *}$ & $(0.008)$ & $-0.022^{* *}$ & $(0.008)$ & $-0.026^{* *}$ & $(0.008)$ & $-0.026^{* *}$ & $(0.008)$ \\
\hline Age & $-0.021^{* * *}$ & $(0.002)$ & $-0.021^{* * *}$ & $(0.002)$ & $-0.021^{* * *}$ & $(0.002)$ & $-0.021^{* * *}$ & $(0.002)$ \\
\hline Having children & $-0.107^{* * *}$ & $(0.032)$ & $-0.107^{* * *}$ & $(0.032)$ & $-0.109 * * *$ & $(0.032)$ & $-0.109 * * *$ & $(0.032)$ \\
\hline $\ln ($ work $h+1)$ & $-0.019^{* *}$ & $(0.006)$ & $-0.019^{* *}$ & $(0.006)$ & $-0.020^{* *}$ & $(0.006)$ & $-0.020^{* *}$ & $(0.006)$ \\
\hline Previous donations & $-0.008^{* * *}$ & $(0.001)$ & $-0.008^{* * *}$ & $(0.001)$ & $-0.008^{* * *}$ & $(0.001)$ & $-0.008^{* * *}$ & $(0.001)$ \\
\hline $\ln ($ Indiv. invit. +1 ) & $0.674^{* * *}$ & $(0.014)$ & $0.674^{* * *}$ & $(0.014)$ & $0.677^{* * *}$ & $(0.014)$ & $0.677^{* * *}$ & $(0.014)$ \\
\hline Permanently deferred & $-0.447^{* * *}$ & $(0.035)$ & $-0.447^{* * *}$ & $(0.035)$ & $-0.452^{* * *}$ & $(0.035)$ & $-0.452^{* * *}$ & $(0.035)$ \\
\hline Subjective norms & 0.021 & $(0.011)$ & 0.021 & $(0.011)$ & 0.016 & $(0.011)$ & 0.016 & $(0.011)$ \\
\hline Self-identity & $0.115^{* * *}$ & $(0.018)$ & $0.115^{* * *}$ & $(0.018)$ & 0.024 & $(0.025)$ & 0.024 & $(0.025)$ \\
\hline Moral norms & $-0.088^{* * *}$ & $(0.013)$ & $-0.088^{* * *}$ & $(0.013)$ & $-0.030^{*}$ & $(0.015)$ & $-0.030^{*}$ & $(0.015)$ \\
\hline Cognitive attitudes & 0.012 & $(0.009)$ & 0.012 & $(0.009)$ & -0.001 & $(0.009)$ & -0.001 & $(0.009)$ \\
\hline GST & & & & & 0.016 & $(0.014)$ & 0.016 & $(0.014)$ \\
\hline Self-efficacy & & & & & $0.038^{* *}$ & $(0.013)$ & $0.038^{* *}$ & $(0.013)$ \\
\hline Constant & $-0.998^{* * *}$ & $(0.069)$ & $-0.998^{* * *}$ & $(0.069)$ & $-0.963^{* * *}$ & $(0.069)$ & $-0.963^{* * *}$ & $(0.069)$ \\
\hline $\ln$ (alpha) & & & -15.002 & & & & -14.198 & \\
\hline$N$ & 24,552 & & 24,552 & & 24,552 & & 24,552 & \\
\hline
\end{tabular}

Notes: Models NB2 (1) and NB2 (2) fail to converge because the dispersion parameter alpha cannot be estimated as it is defined to be positive. Displayed results for these models are therefore based on 10 iterations.

Heteroskedasticity-robust standard errors in parentheses.

${ }^{*} p<0.05,{ }^{* *} p<0.01,{ }^{* * *} p<0.001$ 


\section{S1.4 Additional Results}

Table S4 Results of the CRE Poisson SEM with test for all contextual effects

\begin{tabular}{|c|c|c|c|c|c|c|}
\hline \multirow[b]{2}{*}{ Individuals' donation attempts } & \multicolumn{2}{|c|}{ (1) } & \multicolumn{2}{|c|}{$(2)$} & \multicolumn{2}{|c|}{ (3) } \\
\hline & & & & & & \\
\hline Donation attempts per inhab. & 0.096 & $(0.052)$ & 0.098 & $(0.052)$ & 0.098 & $(0.052)$ \\
\hline Male & $0.479^{* * *}$ & $(0.026)$ & $0.471^{* * *}$ & $(0.026)$ & $0.464^{* * *}$ & $(0.026)$ \\
\hline Income & $-0.041^{* * *}$ & $(0.008)$ & $-0.022^{* *}$ & $(0.008)$ & $-0.027^{* *}$ & $(0.008)$ \\
\hline Age & $-0.019 * * *$ & $(0.002)$ & $-0.021^{* * *}$ & $(0.002)$ & $-0.021^{* * *}$ & $(0.002)$ \\
\hline Having children & $-0.116^{* * *}$ & $(0.033)$ & $-0.109^{* * *}$ & $(0.032)$ & $-0.110^{* * *}$ & $(0.032)$ \\
\hline $\ln$ (working hours+1) & $-0.021^{* * *}$ & $(0.006)$ & $-0.019^{* *}$ & $(0.006)$ & $-0.019 * *$ & $(0.006)$ \\
\hline Previous donations & $-0.007^{* * *}$ & $(0.001)$ & $-0.008^{* * *}$ & $(0.001)$ & $-0.008^{* * *}$ & $(0.001)$ \\
\hline ln(Individuals' invitations +1) & $0.672^{* * *}$ & $(0.014)$ & $0.673^{* * *}$ & $(0.014)$ & $0.675^{* * *}$ & $(0.014)$ \\
\hline Permanently deferred & $-0.474^{* * *}$ & $(0.046)$ & $-0.469^{* * *}$ & $(0.046)$ & $-0.466^{* * *}$ & $(0.046)$ \\
\hline mean_othersdon & 0.038 & $(0.094)$ & 0.018 & $(0.094)$ & 0.027 & $(0.093)$ \\
\hline mean_age & $0.042^{* * *}$ & $(0.002)$ & $0.042^{* * *}$ & $(0.002)$ & $0.042^{* * *}$ & $(0.002)$ \\
\hline mean_children & $0.095^{*}$ & $(0.043)$ & $0.084^{*}$ & $(0.043)$ & $0.100^{*}$ & $(0.043)$ \\
\hline mean_ln_workh & $0.071^{* * *}$ & $(0.012)$ & $0.068^{* * *}$ & $(0.012)$ & $0.070^{* * *}$ & $(0.012)$ \\
\hline mean_ln_i_invit & $-0.242^{* * *}$ & $(0.017)$ & $-0.251^{* * *}$ & $(0.017)$ & $-0.261^{* * *}$ & $(0.017)$ \\
\hline mean_defer & 0.086 & $(0.064)$ & 0.072 & $(0.064)$ & 0.038 & $(0.064)$ \\
\hline Subjective norms & & & 0.007 & $(0.014)$ & 0.002 & $(0.015)$ \\
\hline Self-identity & & & $0.115^{* * *}$ & $(0.021)$ & $0.120^{*}$ & $(0.056)$ \\
\hline Moral norms & & & $-0.073^{* * *}$ & $(0.018)$ & $-0.075^{* *}$ & $(0.026)$ \\
\hline Awareness of need & & & $0.053^{* * *}$ & $(0.015)$ & $0.057^{* * *}$ & $(0.016)$ \\
\hline Cognitive attitudes & & & 0.005 & $(0.010)$ & 0.004 & $(0.011)$ \\
\hline mean_Subnorm & & & 0.031 & $(0.021)$ & 0.016 & $(0.022)$ \\
\hline mean_Selfid & & & $0.071^{*}$ & $(0.029)$ & -0.119 & $(0.063)$ \\
\hline mean_Mornorm & & & -0.029 & $(0.026)$ & 0.062 & $(0.033)$ \\
\hline mean_Awneed & & & -0.017 & $(0.024)$ & $-0.059^{*}$ & $(0.025)$ \\
\hline mean_Cogatt & & & 0.036 & $(0.022)$ & -0.019 & $(0.023)$ \\
\hline Generalized social trust & & & & & -0.109 & $(0.072)$ \\
\hline Self-efficacy & & & & & 0.006 & $(0.023)$ \\
\hline Altruism & & & & & -0.009 & $(0.015)$ \\
\hline Affective attitudes & & & & & 0.009 & $(0.012)$ \\
\hline mean_Gst & & & & & 0.128 & $(0.073)$ \\
\hline mean_Selfeff & & & & & $0.259 * * *$ & $(0.030)$ \\
\hline mean_Altruism & & & & & $-0.073^{* * *}$ & $(0.021)$ \\
\hline mean_Affatt & & & & & $0.058^{* *}$ & $(0.020)$ \\
\hline Constant & $-1.091^{* * *}$ & $(0.069)$ & $-1.011^{* * *}$ & $(0.069)$ & $-0.962^{* * *}$ & $(0.069)$ \\
\hline \multicolumn{7}{|l|}{ Subjective norms } \\
\hline Donation attempts per inhab. & & & & & 0.078 & $(0.043)$ \\
\hline mean_othersdon & & & & & -0.037 & $(0.068)$ \\
\hline Constant & & & & & 0.003 & $(0.009)$ \\
\hline \multicolumn{7}{|l|}{ Self-identity } \\
\hline Donation attempts per inhab. & & & & & 0.007 & $(0.034)$ \\
\hline mean_othersdon & & & & & 0.122 & $(0.067)$ \\
\hline Constant & & & & & -0.007 & $(0.009)$ \\
\hline \multicolumn{7}{|l|}{ Moral norms } \\
\hline Donation attempts per inhab. & & & & & -0.004 & $(0.036)$ \\
\hline
\end{tabular}


Table S4 - Continued from previous page

\begin{tabular}{|c|c|c|c|c|}
\hline \multirow{3}{*}{$\begin{array}{l}\text { mean_othersdon } \\
\text { Constant }\end{array}$} & \multirow[t]{3}{*}{ (1) } & \multirow[t]{3}{*}{ (2) } & \multicolumn{2}{|c|}{ (3) } \\
\hline & & & 0.110 & $(0.067)$ \\
\hline & & & -0.005 & $(0.009)$ \\
\hline \multicolumn{5}{|l|}{ Awareness of need } \\
\hline Donation attempts per inhab. & & & -0.004 & $(0.034)$ \\
\hline mean_othersdon & & & $0.172^{* *}$ & $(0.056)$ \\
\hline Constant & & & -0.007 & $(0.008)$ \\
\hline \multicolumn{5}{|l|}{ Cognitive attitudes } \\
\hline Donation attempts per inhab. & & & 0.040 & $(0.045)$ \\
\hline mean_othersdon & & & 0.059 & $(0.062)$ \\
\hline Constant & & & -0.002 & $(0.007)$ \\
\hline$N$ & 24,552 & 24,552 & 24,552 & \\
\hline \multicolumn{5}{|c|}{$\begin{array}{l}\text { Heteroskedasticity-robust standard errors in parentheses. } \\
{ }^{*} p<0.05,{ }^{* *} p<0.01,{ }^{* *} p<0.001\end{array}$} \\
\hline
\end{tabular}


Table S5 CRE SEM for subsample of donors who ever had a donating partner

\begin{tabular}{|c|c|c|}
\hline \multicolumn{3}{|c|}{ (1) } \\
\hline \multicolumn{3}{|c|}{ Individuals' whole blood donation attempts } \\
\hline Donation attempts per peer & $0.350^{* * *}$ & $(0.078)$ \\
\hline Male & $0.425^{* * *}$ & $(0.054)$ \\
\hline Income & $-0.034^{*}$ & $(0.016)$ \\
\hline Age & $-0.021^{* * *}$ & $(0.004)$ \\
\hline Having children & $-0.094^{*}$ & $(0.045)$ \\
\hline $\ln$ (working hours+1) & 0.019 & $(0.013)$ \\
\hline Previous donations & $-0.008^{* * *}$ & $(0.001)$ \\
\hline ln(Individuals' invitations +1) & $0.669^{* * *}$ & $(0.030)$ \\
\hline Permanently deferred & $-0.345^{* * *}$ & $(0.066)$ \\
\hline Subjective norms & 0.016 & $(0.018)$ \\
\hline Self-identity & -0.039 & $(0.056)$ \\
\hline Moral norms & 0.028 & $(0.045)$ \\
\hline Awareness of need & $0.115^{*}$ & $(0.047)$ \\
\hline Cognitive attitudes & -0.122 & $(0.071)$ \\
\hline Generalized social trust & 0.067 & $(0.052)$ \\
\hline Self-efficacy & $0.145^{* *}$ & $(0.045)$ \\
\hline Altruism & $-0.143^{* *}$ & $(0.053)$ \\
\hline Affective attitudes & 0.019 & $(0.025)$ \\
\hline Constant & $-0.795^{* * *}$ & $(0.130)$ \\
\hline \multicolumn{3}{|l|}{ Subjective norms } \\
\hline Donation attempts per peer & 0.101 & $(0.059)$ \\
\hline Constant & $-0.033^{*}$ & $(0.015)$ \\
\hline \multicolumn{3}{|l|}{ Self-identity } \\
\hline Donation attempts per peer & -0.007 & $(0.063)$ \\
\hline Constant & $-0.044^{* *}$ & $(0.014)$ \\
\hline \multicolumn{3}{|l|}{ Moral norms } \\
\hline Donation attempts per peer & -0.052 & $(0.052)$ \\
\hline Constant & -0.014 & $(0.011)$ \\
\hline \multicolumn{3}{|l|}{ Awareness of need } \\
\hline Donation attempts per peer & -0.019 & $(0.040)$ \\
\hline Constant & -0.012 & $(0.007)$ \\
\hline \multicolumn{3}{|l|}{ Cognitive attitudes } \\
\hline Donation attempts per peer & $0.034^{* *}$ & $(0.012)$ \\
\hline Constant & -0.002 & $(0.003)$ \\
\hline$N$ & 7,006 & \\
\hline
\end{tabular}




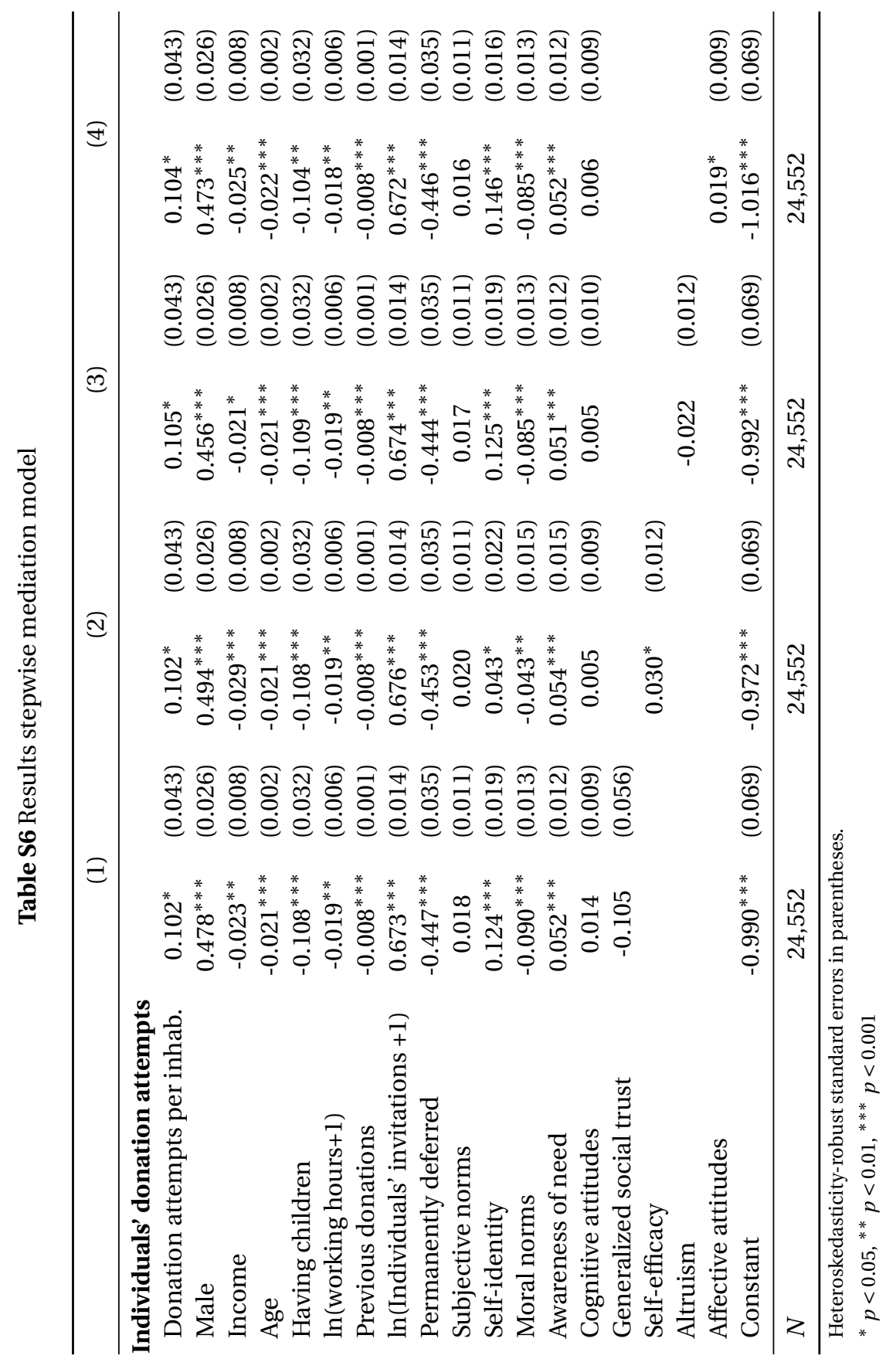




\section{References}

Buis, Maarten L. (2011). HANGROOT: Stata module creating a hanging rootogram comparing an empirical distribution to the best fitting theoretical distribution.

Cameron, A. Colin and Pravin K. Trivedi (2013). Regression Analysis of Count Data. 2nd ed. Econometric Society Monographs. Cambridge: Cambridge University Press. 